\title{
In-canopy gas-phase chemistry during CABINEX 2009: sensitivity of a 1-D canopy model to vertical mixing and isoprene chemistry
}

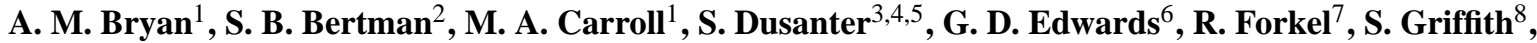 \\ A. B. Guenther ${ }^{9}$, R. F. Hansen ${ }^{8}$, D. Helmig ${ }^{10}$, B. T. Jobson ${ }^{11}$, F. N. Keutsch ${ }^{12}$, B. L. Lefer ${ }^{13}$, S. N. Pressley ${ }^{11}$, \\ P. B. Shepson ${ }^{14,15}$, P. S. Stevens ${ }^{8}$, and A. L. Steiner ${ }^{1}$ \\ ${ }^{1}$ Department of Atmospheric, Oceanic, and Space Sciences, University of Michigan, Ann Arbor, Michigan, 48109, USA \\ ${ }^{2}$ Department of Chemistry, Western Michigan University, Kalamazoo, Michigan, 49008, USA \\ ${ }^{3}$ School of Public and Environmental Affairs, Indiana University, Bloomington, Indiana, 47405, USA \\ ${ }^{4}$ EMDouai, CE, 59508 Douai, France \\ ${ }^{5}$ Univ Lille Nord de France, 59000, Lille, France \\ ${ }^{6}$ Department of Chemistry, Eastern Michigan University, Ypsilanti, Michigan, 48197, USA \\ ${ }^{7}$ Karlsruhe Institute of Technology (KIT), IMK-IFU, 82467 Garmisch-Partenkirchen, Germany \\ ${ }^{8}$ Department of Chemistry, Indiana University, Bloomington, Indiana, 47405, USA \\ ${ }^{9}$ Atmospheric Chemistry Division, National Center for Atmospheric Research, Boulder, Colorado, 80307, USA \\ ${ }^{10}$ Institute of Arctic and Alpine Research, University of Colorado, Boulder, Colorado, 80309, USA \\ ${ }^{11}$ Department of Civil \& Environmental Engineering, Washington State University, Pullman, Washington, 99164, USA \\ ${ }^{12}$ Department of Chemistry, University of Wisconsin, Madison, Wisconsin, 53706, USA \\ ${ }^{13}$ Department of Earth and Atmospheric Sciences, University of Houston, Houston, Texas, 77004, USA \\ ${ }^{14}$ Department of Chemistry, Purdue University, West Lafayette, Indiana, 47907, USA \\ ${ }^{15}$ Department of Earth and Atmospheric Sciences, Purdue University, West Lafayette, Indiana, 47907, USA
}

Correspondence to: A. M. Bryan (ambrya@umich.edu)

Received: 22 February 2012 - Published in Atmos. Chem. Phys. Discuss.: 22 May 2012

Revised: 30 August 2012 - Accepted: 17 September 2012 - Published: 28 September 2012

\begin{abstract}
Vegetation emits large quantities of biogenic volatile organic compounds (BVOC). At remote sites, these compounds are the dominant precursors to ozone and secondary organic aerosol (SOA) production, yet current field studies show that atmospheric models have difficulty in capturing the observed $\mathrm{HO}_{\mathrm{x}}$ cycle and concentrations of BVOC oxidation products. In this manuscript, we simulate BVOC chemistry within a forest canopy using a one-dimensional canopy-chemistry model (Canopy Atmospheric CHemistry Emission model; CACHE) for a mixed deciduous forest in northern Michigan during the CABINEX 2009 campaign. We find that the base-case model, using fully-parameterized mixing and the simplified biogenic chemistry of the Regional Atmospheric Chemistry Model (RACM), underestimates daytime in-canopy vertical mixing by $50-70 \%$ and by an order of magnitude at night, leading to discrepancies in the diurnal evolution of $\mathrm{HO}_{\mathrm{x}}, \mathrm{BVOC}$, and $\mathrm{BVOC}$ oxidation
\end{abstract}

products. Implementing observed micrometeorological data from above and within the canopy substantially improves the diurnal cycle of modeled BVOC, particularly at the end of the day, and also improves the observation-model agreement for some BVOC oxidation products and $\mathrm{OH}$ reactivity. We compare the RACM mechanism to a version that includes the Mainz isoprene mechanism (RACM-MIM) to test the model sensitivity to enhanced isoprene degradation. RACM-MIM simulates higher concentrations of both primary BVOC (isoprene and monoterpenes) and oxidation products ( $\mathrm{HCHO}$, MACR+MVK) compared with RACM simulations. Additionally, the revised mechanism alters the $\mathrm{OH}$ concentrations and increases $\mathrm{HO}_{2}$. These changes generally improve agreement with $\mathrm{HO}_{\mathrm{x}}$ observations yet overestimate BVOC oxidation products, indicating that this isoprene mechanism does not improve the representation of local chemistry at the site. Overall, the revised mechanism yields smaller changes in 
BVOC and BVOC oxidation product concentrations and gradients than improving the parameterization of vertical mixing with observations, suggesting that uncertainties in vertical mixing parameterizations are an important component in understanding observed BVOC chemistry.

\section{Introduction}

There is increasing evidence of the important role of forest canopies and biogenic volatile organic compound (VOC) emissions on tropospheric composition and atmospheric chemistry (Goldstein and Galbally, 2007; Lelieveld et al., 2008). VOC oxidation, in the presence of reactive nitrogen oxides $\left(\mathrm{NO}_{\mathrm{x}}=\mathrm{NO}+\mathrm{NO}_{2}\right)$ and sunlight, is critical for ozone formation (Logan, 1985) and condensation of their oxidation products can yield secondary organic aerosols (SOA) (Claeys et al., 2004; Carlton et al., 2009; Hallquist et al., 2009). Additionally, VOC can control the oxidation capacity of the troposphere through the regulation of hydrogen radicals $\left(\mathrm{HO}_{\mathrm{x}}=\mathrm{OH}+\mathrm{HO}_{2}\right)$ (Poisson et al., 2000; Tan et al., 2001). Forest canopies are an important VOC source both globally and regionally, contributing to nearly half the global VOC budget (Guenther et al., 1995). To affect the troposphere, biogenic VOC (BVOC) emissions and their oxidation products must be mixed effectively out of the forest canopy. This forest-atmosphere exchange is highly sensitive to turbulent mixing and chemistry because BVOC oxidation and transport occur on similar timescales (Molemaker and VilàGuerau de Arellano, 1998; Krol et al., 2000; Pugh et al., 2010).

To investigate the role of BVOC on tropospheric chemistry, several recent field campaigns have involved chemical measurements at multiple heights throughout the forest canopy (e.g., Carroll et al., 2001; Hewitt et al., 2010; Martin et al., 2010). Results from these field campaigns highlight gaps in our understanding of BVOC oxidation. For example, the hydroxyl radical $(\mathrm{OH})$ is underestimated in most forest ecosystem types (Carslaw and Carslaw, 2001; Tan et al., 2001; Butler et al., 2008; Karl et al., 2009). Modeling studies of remote forest sites that add a $\mathrm{HO}_{\mathrm{x}}$ recycling mechanism through BVOC oxidation reactions (Lelieveld et al., 2008; Hofzumahaus et al., 2009) or $\mathrm{OH}$ regeneration from epoxides (Paulot et al., 2009) display some improvement in measuredmodeled agreement in some locations, yet these do not show consistent improvement in all studies (Karl et al., 2009; Barkley et al., 2011). Additionally, BVOC oxidation products are poorly simulated in a number of forest regimes. Pugh et al. (2010) show that first-generation oxidation products of isoprene $\left(\mathrm{C}_{5} \mathrm{H}_{8}, 2\right.$-methyl-1,3-butadiene $)$-the dominant BVOC emission in many broadleaf ecosystems - are overestimated by box-model simulations of a Malaysian tropical rainforest. Karl et al. (2009) compare several mechanisms with enhanced isoprene oxidation and find that some iso- prene oxidation products such as hydroxyacetone are underpredicted compared to observations. While revised chemical mechanisms can explicitly account for more detailed isoprene chemistry (Pöschl et al., 2000; Paulot et al., 2009; Peeters et al., 2009; Stavrakou et al., 2010), difficulties remain in simulating isoprene degradation and oxidation products under low- $\mathrm{NO}_{\mathrm{x}}$ conditions (Karl et al., 2009).

In addition to uncertainties in the pathways of BVOC oxidation, vertical transport within and above the canopy sub-layer is an additional source of uncertainty in forestatmosphere exchange (Finnigan, 2000; Hurst et al., 2001). Here, we define the canopy sub-layer as the thin atmospheric layer nearest the surface containing forest roughness elements. Turbulence occurs over a range of scales in the planetary boundary layer (PBL) from the mesoscale to the sub-grid scale, and thus, must be either represented with higher-order turbulence schemes or parameterizations. Among the most common parameterizations is the first-order flux-gradient relationship, known as K-theory, in which turbulent exchange is a function of the eddy diffusivity parameter, $K$ (Blackadar, 1979). Because mixing strength in the mid-PBL peaks at two orders of magnitude higher than in the canopy roughness layer (Gao et al., 1993), turbulent transport tends to be much smaller within plant canopies than above the roughness elements. In fact, K-theory has been found to break down completely within forest canopies due to the existence of intermittent coherent structures that encompass the entire depth of the canopy (Raupach et al., 1996), yet the parameterization continues to be used for its computational efficiency in many models (Forkel et al., 2006). Though high-resolution canopy models may have the vertical resolution to capture fine-scale turbulence within the canopy, many models do not have the detailed description of higher-order turbulence to simulate the effects of coherent structures and other canopy-scale turbulence. Therefore, most models have large uncertainties in the role of vertical mixing on BVOC gradients and forestatmosphere exchange (e.g., Ganzeveld et al., 2006). Nearfield effects, often represented by a scaling factor (Makar et al., 1999; Stroud et al., 2005; Wolfe and Thornton, 2011), have been shown to improve modeled in-canopy and abovecanopy turbulence (Raupach, 1989). Large-eddy simulation models (e.g., Heus et al., 2010; Patton et al., 2001) can capture these dynamical changes, though development with sufficient detail in chemical mechanisms is still underway (e.g., Kim et al., 2012). The use of a 1-D model in this study represents a computationally efficient preference towards a detailed chemical mechanism over that of a detailed turbulence parameterization.

Despite the uncertainties in vertical mixing, onedimensional (1-D) models are still useful tools for studying the vertical transport in the context of atmospheric composition because they focus on the implications of in-canopy chemistry on vertical concentrations and gradients (e.g., Wolfe et al., 2011; Boy et al., 2011). Wolfe et al. (2011) examine daytime biogenic chemistry at a ponderosa pine 
plantation, concluding that chemistry may outweigh the effect of turbulent mixing on forest-atmosphere exchange, even for compounds with long chemical lifetimes relative to their transport timescales. Boy et al. (2011) applies a more detailed turbulence scheme to understand BVOC oxidation and tracer transport and their effect on particle formation in a Scots Pine forest in Finland and find that this improved mixing parameterization can reproduce observed vertical profiles of BVOC.

Here, we focus on chemistry and turbulence within and above a deciduous hardwood forest in Northern Michigan. A number of field campaigns as part of the Program for Research on Oxidants: PHotochemistry, Emissions, and Transport (PROPHET, Carroll et al., 2001) have been conducted since 1997 at the University of Michigan Biological Station (UMBS). Results from the summer 1998 PROPHET intensive show that models underestimate $\mathrm{OH}$ (Faloona et al., 2001; Sillman et al., 2002), while measured $\mathrm{HO}_{2}$ concentrations compare well with model results (Tan et al., 2001). Measurements of $\mathrm{OH}$ reactivity suggest an unknown BVOC source, which may contribute to these $\mathrm{OH}$ discrepancies (Di Carlo et al., 2004). In 2009, the Community AtmosphereBiosphere INteractions Experiment (CABINEX) was conducted to provide new insights into the role of BVOC chemistry and its relationship to $\mathrm{HO}_{\mathrm{x}}$ chemistry observed at the PROPHET site. Branch enclosure measurements from CABINEX 2009 show that identified primary emissions reasonably reflect current emission estimates (Ortega et al., 2007), suggesting that the missing ambient $\mathrm{OH}$ reactivity could be explained by secondary BVOC oxidation products (Kim et al., 2011).

In this manuscript, we compare measurements from the CABINEX 2009 campaign with a 1-D Eulerian Canopy Atmospheric CHemistry Emission model (CACHE, Forkel et al., 2006) to investigate the role of in-canopy chemistry and turbulence on $\mathrm{HO}_{\mathrm{x}}$ and $\mathrm{BVOC}$ concentrations and vertical gradients. To examine the relative sensitivities of the model to mixing and chemistry, we compare a base-case model scenario with the original turbulence and chemistry description within CACHE against a revised mixing scheme and isoprene-focused chemical mechanism. We explore the relative impacts of $\mathrm{HO}_{\mathrm{x}}$ pathways in an atmospheric chemical mechanism versus the effects of vertical mixing on ambient concentrations to isolate and highlight the key processes of biosphere-atmosphere interactions at this deciduous forest ecosystem.

\section{Methods}

\subsection{CABINEX 2009 campaign}

CABINEX 2009 was conducted at the PROPHET site at UMBS near Pellston, MI $\left(45^{\circ} 33^{\prime} 31.66^{\prime \prime} \mathrm{N}\right.$, $84^{\circ} 43^{\prime} 52.40^{\prime \prime} \mathrm{W}$ ) at the transition between mixed hardwood to boreal forest (Schmid et al., 2003). Depending on the wind direction, the site can be controlled by local emissions and chemistry or regional transport from urban areas (Milwaukee, WI ( $\sim 378 \mathrm{~km} \mathrm{SW})$; Detroit, MI ( $\sim 385 \mathrm{~km} \mathrm{SSE})$; and Chicago, IL ( $\sim 475 \mathrm{~km} \mathrm{SW})$, as shown in Fig. S2). The local vegetation is diverse (Pressley et al., 2005), containing varieties of aspen, oak, beech, birch, maple, and pine with an average canopy height $(h)$ of approximately $22.5 \mathrm{~m}$. Climate conditions at the PROPHET site are generally cold but with warm summers (FLUXNET database, Baldocchi et al., 2001). The average daily maximum temperatures for Pellston, MI, in July and August are $26^{\circ} \mathrm{C}$ and $25^{\circ} \mathrm{C}$ with average precipitation of $63.2 \mathrm{~mm}$ and $81.8 \mathrm{~mm}$, respectively. The summer of 2009 was unseasonably cool and cloudy with an average high temperature of $22^{\circ} \mathrm{C}$ and with rain or fog occurring on $62 \%$ of the days within the 1 July- 8 August 2009 observational period, which may reduce BVOC emissions and photochemical activity.

$\mathrm{O}_{3}, \mathrm{NO}_{2}$, NO, isoprene, monoterpenes, formaldehyde (HCHO), methacrolein and methyl vinyl ketone (MACR+MVK), $\mathrm{OH}, \mathrm{HO}_{2}$, and glyoxal (GLY) were measured at multiple heights within and above the canopy. Due to limited instrumentation during the campaign, simultaneous measurements at multiple heights could not be obtained for all compounds. Therefore, data availability at a given height widely varies over the campaign. Primary BVOC species and BVOC oxidation products were measured, alternating at 10-min intervals between $6 \mathrm{~m}, 20.4 \mathrm{~m}$, and $34 \mathrm{~m}$, using a proton transfer reaction mass spectrometer (PTR-MS) with dehumidified sampling to allow more sensitive measurement of HCHO (de Gouw and Warneke, 2007; Jobson and McCoskey, 2010). $\mathrm{NO}$ and $\mathrm{NO}_{2}$ were measured, alternating between the same three heights, using a 2-channel chemiluminescence instrument with a blue light photolytic converter for $\mathrm{NO}_{2}$ (Air Quality Design). $\mathrm{HO}_{\mathrm{x}}$ species were measured only at $32 \mathrm{~m}$ during the two-day simulation presented here, with $\mathrm{OH}$ measured using laser-induced fluorescence with the Fluorescence Assay by Gas Expansion (FAGE) technique and $\mathrm{HO}_{2}$ measured by chemical conversion to OH with added NO (Stevens et al., 1994; Dusanter et al., 2009). Total $\mathrm{OH}$ reactivity was measured at $30.9 \mathrm{~m}$ using a turbulent flow tube technique similar to that described in Kovacs and Brune (2001). Glyoxal (GLY) was measured at $35.4 \mathrm{~m}$ using laser-induced phosphorescence (Huisman et al., 2011). Wind speed and direction were measured via propeller anemometer at $36.4 \mathrm{~m}$. Additionally, two sonic anemometers measuring the three-component wind field $(u$, $v$, and $w$ ) and temperature were mounted at $20.6 \mathrm{~m}$ and $34 \mathrm{~m}$ (Steiner et al., 2011). Temperature was also measured at $6 \mathrm{~m}$, $20.4 \mathrm{~m}$, and $31.2 \mathrm{~m}$ using R. M. Young relative humidity and temperature probes. Photosynthetically active radiation (PAR) was measured at $32.6 \mathrm{~m}$ using a BF-3 Sunshine Sensor. 


\subsection{Model description and simulations}

CACHE is a 1-D multilayer model that simulates the vertical distribution of concentrations and vertical fluxes of heat, moisture, and gas-phase chemical species over time using the prognostic equations for potential temperature $(\theta)$ and volume mixing ratio for compound $i\left(c_{i}\right)$ :

$$
\begin{aligned}
& \frac{\partial \theta}{\partial t}=\frac{\partial}{\partial z}\left(K_{\mathrm{H}} \frac{\partial \theta}{\partial z}\right)+S_{\mathrm{H}} \\
& \frac{\partial c_{i}}{\partial t}=\frac{\partial}{\partial z}\left(K_{\mathrm{H}} \frac{\partial c_{i}}{\partial z}\right)+S_{\mathrm{c}}+C
\end{aligned}
$$

Equations (1) and (2) are solved for each model layer, where $K_{\mathrm{H}}$ denotes the turbulent exchange coefficient for heat, $S_{\mathrm{H}}$ and $S_{c}$ denote sources and sinks for heat and mass, respectively, and $C$ denotes chemical transformation. Turbulent exchange, chemistry, emissions, deposition, and advection are described in subsequent sections.

For our simulations of the PROPHET site, we use a model domain consisting of 40 vertical layers spanning $4.4 \mathrm{~km}$ in the vertical $(z)$ direction with eight layers in the 6-m trunk space and ten layers in the $16.5-\mathrm{m}$ crown space. The grid resolution decreases exponentially with height with a spacing of $0.81 \mathrm{~m}$ at ground level and $1061.1 \mathrm{~m}$ at the top. Simulations are run for $48 \mathrm{~h}$ at a time step of $60 \mathrm{~s}$. Initial conditions are provided to the model for vertical profiles of chemical concentrations based on observed near-canopy concentrations at the start of the simulation; the initial vertical temperature profile is interpolated using radiosonde data from Gaylord, MI ( $\sim 59.5 \mathrm{~km} \mathrm{~S})$. Model input includes (Fig. S1 in the Supplement): (1) observed PAR to drive the prognostic temperature profile and photochemistry and account for cloud cover, and (2) observed wind speed and direction at $36.4 \mathrm{~m}$ to drive the vertical wind profile and $\mathrm{NO}_{\mathrm{x}}$ and VOC advection. Additional input required for the revised turbulence scheme (see Sect. 2.2.1) include $u_{*}$ and $\sigma_{w}$ at 20.6 and $34 \mathrm{~m}$. In addition, we prescribe a total leaf area index (LAI) of $3.8 \mathrm{~m}^{2} \mathrm{~m}^{-2}$ (as observed at PROPHET, Ortega et al., 2007) and typical values for leaf reflectance and transmittance observed in deciduous broadleaf ecosystems (see Table 1, Asner, 1998). Model output is interpolated at the instrument heights and data collection times for precise comparison with measurements.

\subsubsection{Turbulent exchange}

Vertical transport is parameterized in CACHE using a firstorder flux-gradient relationship, or K-theory, in which heat and mass are transported by eddy diffusion at a rate proportional to the turbulent exchange coefficient for heat, $K_{\mathrm{H}}$. Vertical fluxes of heat and mass are computed at each model time step as follows:

$\overline{w^{\prime} \theta^{\prime}}=-K_{\mathrm{H}} \frac{\partial \bar{\theta}}{\partial z}$
Table 1. Leaf and soil reflectance and transmittance by waveband (visible/near infrared/thermal) used in CACHE. Absorptivities are $1-$ (reflectance + transmittance). Values are derived from Asner (1998).

\begin{tabular}{lcc}
\hline & Soil & Leaf \\
\hline Reflectance & $0.15 / 0.20 / 0.10$ & $0.20 / 0.45 / 0.10$ \\
Transmittance & $0.00 / 0.00 / 0.00$ & $0.10 / 0.30 / 0.10$ \\
\hline
\end{tabular}

$\overline{w^{\prime} c_{i}^{\prime}}=-K_{\mathrm{H}} \frac{\partial \overline{c_{i}}}{\partial z}$.

Modeled $K_{\mathrm{H}}$ (hereinafter denoted $K_{\mathrm{H} \text {,mod }}$ ) is derived empirically according to Forkel et al. (1990) given a length scale $l$, the vertical wind shear $|\partial v / \partial z|$, and a stability parameter $f:$

$K_{\mathrm{H}, \bmod }=l^{2}\left|\frac{\partial v}{\partial z}\right| \cdot f$.

$l$ varies within and above the canopy according to the following parameterization:

$l=\frac{\kappa(z-d)}{1+(\kappa(z-d) / \lambda)}$

where $\kappa$ is the von Kármán constant (0.4), $d$ is the zero-plane displacement height $(0.85 h$ for $z \geq h$ and zero for $z<h)$, and $\lambda$ is the maximum mixing length (given by Forkel et al. (1990, Eq. (10)) for $z \geq h$ and set constant at $2 \mathrm{~m}$ for $z<$ $h)$. The vertical wind profile for computing $|\partial v / \partial z|$ derives from the common logarithmic expression for the PBL (Stull, 1988); within the canopy, winds dissipate as a function of $u_{*}$ and canopy structure according to a modified logarithmicwind equation following Baldocchi (1988, Eq. 6). $f$ is a function of the Richardson number Ri:

$f(\mathrm{Ri})=\left\{\begin{array}{ll}1.35 \sqrt{1-11 \mathrm{Ri}} \frac{1-5.5 \mathrm{Ri}}{1-3 \mathrm{Ri}} \quad: \mathrm{Ri}<0 \\ 1.35[(1+6 \mathrm{Ri}) \sqrt{1+6 \mathrm{Ri}}]^{-1}: \mathrm{Ri} \geq 0\end{array}\right.$.

In the original model configuration-hereafter referred to as the "BASE" model scenario - the vertical turbulence profile is driven solely by Eqs. (5-7).

To evaluate the sensitivity of BVOC gradients to in-canopy vertical mixing, we apply a modified K-theory parameterization in a modeling scheme hereafter referred to as the "MIX" simulation. We first define "observed" $K_{\mathrm{H}}$ (hereafter denoted by $K_{\mathrm{H}, \mathrm{obs}}$ ) following Makar et al. (1999):

$K_{\mathrm{H}, \mathrm{obs}}=\sigma_{w}^{2} T_{\mathrm{L}}$

where $T_{\mathrm{L}}$ is the Lagrangian timescale $\left(T_{\mathrm{L}}=0.3 h / u_{*}\right), u_{*}$ is the friction velocity, and $\sigma_{w}$ is the vertical velocity standard deviation. $u_{*}$ and $\sigma_{w}$ are computed using half-hour Reynolds 
averages of raw $(10 \mathrm{~Hz})$ sonic anemometer measurements of $u, v$, and $w$ above the canopy $(34 \mathrm{~m} ; 1.5 h)$ and in the top of the canopy $(20.6 \mathrm{~m} ; 0.9 h)$ :

$u_{*}=\left({\overline{u^{\prime} w^{\prime}}}^{2}+{\overline{v^{\prime} w^{\prime}}}^{2}\right)^{1 / 4}$

$\sigma_{w}=\sqrt{\frac{1}{n-1} \sum_{i=1}^{n}\left(w_{i}-\bar{w}\right)^{2}}$

In the MIX simulations, we adjust the modeled turbulence profile (i.e. the BASE case) to match the near-surface observations estimated in Eq. (8) as follows. At each time step, we first compute a full vertical profile of $K_{\mathrm{H} \text {,mod }}$ using Eq. (5). Then, we linearly interpolate between $K_{\mathrm{H}, \bmod }$ at the canopy base $(6 \mathrm{~m})$ and $K_{\mathrm{H}, \mathrm{obs}}$ at the first measurement level $(20.6 \mathrm{~m})$. At the model grid points between the two measurement heights (20.6-34 m), we linearly interpolate $u_{*}$ and $\sigma_{w}$ and compute $K_{\mathrm{H}, \mathrm{obs}}$ using Eq. (8). Above $34 \mathrm{~m}$, modeled values are adjusted to remove any discontinuity between the measured and modeled values. Near-canopy $K_{\mathrm{H}}(z \leq 1.64 h)$ is scaled by an $R$ factor to account for nearfield effects of the canopy, where $R$ is:

$R=\frac{\left[1-\exp \left(-\tau / T_{\mathrm{L}}\right)\right]\left(\tau-T_{\mathrm{L}}\right)^{3 / 2}}{\left[\tau-T_{\mathrm{L}}+T_{\mathrm{L}} \exp \left(-\tau / T_{\mathrm{L}}\right)\right]^{3 / 2}}$

and the transport timescale $\tau$ is derived using a $\tau / T_{\mathrm{L}}$ ratio of 4 (Stroud et al., 2005; Wolfe and Thornton, 2011). We evaluate the revised mixing scheme in Sect. 3.1.

\subsubsection{Chemistry}

Gas-phase chemical transformation in the original CACHE model implements the Regional Atmospheric Chemistry Mechanism (RACM, Stockwell et al., 1997), which includes a suite of 77 chemical species and 237 reactions. The mechanism includes explicit treatment of three BVOC categories: isoprene (denoted by the RACM surrogate, ISO), monoterpenes with one double bond (i.e. $\alpha$-pinene; denoted API), and monoterpenes with two double bonds (i.e. $d$-limonene; denoted LIM). The remaining VOC are lumped into four alkane categories, four alkene categories, and three aromatic categories based on reactivity with $\mathrm{OH}$. In the RACM mechanism, MACR+MVK are contained in the surrogate for all unsaturated C4 carbonyls (denoted MACR in Stockwell et al. (1997)), which derive from both anthropogenic and biogenic diene oxidation; however, we note that measurements from the campaign only account for MACR+MVK alone.

In this study, we perform a sensitivity test (hereafter referred to as the "MIM" simulation) comparing RACM against the Mainz isoprene mechanism (MIM) adaptation of RACM (RACM-MIM, Geiger et al., 2003). RACM-MIM treats an additional seven species explicitly that are split from surrogate species in RACM. By using this greater speciation, RACM-MIM includes an additional twelve reactions. Ultimately, this mechanism provides more specific pathways of isoprene oxidation, the production of second-generation isoprene oxidation products, and further detail on the MACR chemistry under low- $\mathrm{NO}_{\mathrm{x}}$ conditions.

\subsubsection{Emissions}

BVOC emissions are controlled by site-specific emission rates that depend on ecosystem-specific emission factors, temperature, and PAR (Steinbrecher et al., 1999). Isoprene emission fluxes were not routinely measured during the campaign; therefore, we use the mean isoprene surface emission flux observed at PROPHET during 2003 and 2005 (Ortega et al., 2007). Bigtooth aspen (Populus grandidentata) and northern red oak (Quercus rubra) account for $99 \%$ of the isoprene budget, emitting at mean basal emission rates of 46.3 and $53.5 \mu \mathrm{g} \mathrm{Cg}^{-1} \mathrm{~h}^{-1}$ at standard conditions (PAR $=1000 \mu \mathrm{mol} \mathrm{m}^{-2} \mathrm{~s}^{-1}$; temperature $=30^{\circ} \mathrm{C}$ ). Since 2009 was colder than average summers, we subtract one standard deviation from the mean isoprene emission fluxes, corresponding to $24.8 \mu \mathrm{g} \mathrm{Cg}^{-1} \mathrm{~h}^{-1}$ for aspen and $23.8 \mu \mathrm{g} \mathrm{g} \mathrm{g}^{-1} \mathrm{~h}^{-1}$ for oak. The net emission of isoprene per model level is determined by scaling the given emission factors by PAR and temperature, according to the parameterization described in Forkel et al. (2006) following Guenther et al. (1995), and a prescribed vertical LAI distribution. Monoterpene emission rates derive from tree branch enclosure measurements in 2003, 2005 and 2009 (Ortega et al., 2007; Ortega and Helmig, 2008). Normalized $\left(20^{\circ} \mathrm{C}\right)$ foliage emission rates for the sum of monoterpenes for northern red oak (Quercus rubra), eastern white pine (Pinus strobus), red pine (Pinus resinosa), and American beech (Fagus grandifolia) measured during CABINEX 2009 are 0.16, 0.38, 0.56, and $7.46 \mu \mathrm{g} \mathrm{Cg}^{-1} \mathrm{~h}^{-1}$, respectively. For beech, the predominant emission is $d$-limonene ( $27 \%$ ), followed by sabinene (17\%), $\alpha$-pinene (12\%), and cymene (12\%). Ortega et al. (2007) measure a mean basal emission rate for paper birch (Betula papyrifera) of $0.5 \mu \mathrm{g} \mathrm{g}^{-1} \mathrm{~h}^{-1}$. For white and red pine, we scale the emission factors by 2.56 (Perterer and Körner, 1990) to account for the conversion from projected to total leaf area. We sum these species contributions and split this total monoterpene emission factor into the RACM species API $\left(56.5 \%\right.$, or $0.086 \mathrm{nmol} \mathrm{m}^{-2}$ leaf area $\left.\mathrm{s}^{-1}\right)$ and LIM $\left(43.5 \%\right.$, or $0.066 \mathrm{nmolm}^{-2}$ leafarea s${ }^{-1}$ ) according to the measured fractional contribution of similar species.

We note that these emission estimates are based on available data from the site collected by several investigators over several seasons. Due to the high variability seen in these data, it is difficult to define representative values particularly given the cool conditions during the summer of 2009 . Previous studies have noted that emission factors can vary based on prior temperatures on the span of weeks (Pétron et al., 2001) and can vary based on the plants acclimation, 
particularly for isoprene (Hanson and Sharkey, 2001). Consequently, these estimates may have uncertainties of a minimum of a factor of two. Measurements indicate a dependence on temperature for monoterpene emissions; therefore, we presume monoterpene emissions to be from pools within the foliage, and are, thus, scaled according to the temperaturedependent parameterization described in Forkel et al. (2006). Soil NO emissions are parameterized according to Forkel et al. (2006), following Simpson et al. (1995), based on an emission rate of $180 \mathrm{nmolm}^{-2} \mathrm{~h}^{-1}$ observed previously at PROPHET (Alaghmand et al., 2011). Foliage $\mathrm{NO}_{2}$ emission from nitrate photolysis at the leaf surface (Hari et al., 2003) is not considered in this study due to uncertainties in emission factors.

\subsubsection{Deposition}

Dry deposition of chemical species to canopy foliage $\left(S_{c, \text { dep }, i} ; \mathrm{nmol} \mathrm{m}^{-2} \mathrm{~s}^{-1}\right)$ is parameterized following Meyers and Baldocchi (1988):

$S_{\mathrm{c}, \mathrm{dep}, i}(z)=-\operatorname{LAI}(z) c_{i}(z) v_{\mathrm{d}, i}(z)$

where LAI and $c_{i}$ are the leaf area index per unit height and concentration for gas $i$, respectively. Deposition velocity $\left(v_{\mathrm{d}, i} ; \mathrm{m} \mathrm{s}^{-1}\right)$ is represented by four resistances: the quasi-laminar boundary layer $\left(R_{\mathrm{b}, i}\right)$, stomatal $\left(R_{\mathrm{S}}\right)$, mesophyll $\left(R_{\mathrm{m}, i}\right)$, and cuticular $\left(R_{\mathrm{c}, i}\right)$ :

$v_{\mathrm{d}, i}(z)=\frac{1}{R_{\mathrm{b}, i}(z)+R_{\mathrm{s}}(z) D_{\mathrm{H}_{2} \mathrm{O}} / D_{i}+R_{\mathrm{m}, i}}+\frac{2}{R_{\mathrm{b}, i}(z)+R_{\mathrm{c}, i}}$.

where $D_{\mathrm{H}_{2} \mathrm{O}} / D_{i}$ is the ratio of the molecular diffusivities of water to gas $i$ (Gao et al., 1993). $R_{\mathrm{b}, i}$ is a function of $D_{\mathrm{H}_{2} \mathrm{O}} / D_{i}$ and the layer-mean horizontal wind $\bar{u}$ (Meyers, 1987):

$R_{\mathrm{b}, \mathrm{i}}(z)=\frac{r_{\mathrm{b}}(z)}{D_{\mathrm{H}_{2} \mathrm{O}} / D_{i}}$.

where

$r_{\mathrm{b}}(z)= \begin{cases}500 & : \bar{u}(z) \leq 0.01 \mathrm{~m} \mathrm{~s}^{-1} \\ 180 \sqrt{l / \bar{u}(z)}: \bar{u}(z)>0.01 \mathrm{~m} \mathrm{~s}^{-1}\end{cases}$

given an estimated typical leaf length $l$ of $8 \mathrm{~cm} . R_{\mathrm{S}}$ is dependent on light, leaf temperature, and water potentials during the day, following Jarvis (1976), and is equivalent to the cuticular resistance for $\mathrm{O}_{3}\left(R_{\mathrm{c}, \mathrm{O}_{3}} \approx 3000 \mathrm{~m} \mathrm{~s}^{-1}\right.$, Wesely, 1989) at night. $R_{\mathrm{m}, i}$ and $R_{\mathrm{c}, i}$ are parameterized according to Wesely (1989) as a function of the Henry's law constant $H_{i}^{*}$ and a reactivity factor $f_{0, i}$ describing the extent that gas $i$ decomposes in the plant mesophyll relative to $\mathrm{O}_{3}$, ranging from non-reactive $\left(f_{0, i}=0\right)$ to full decomposition $\left(f_{0, i}=1\right.$, i.e. $\left.\mathrm{O}_{3}\right)$ :

$R_{\mathrm{m}, i}=\left(H_{i}^{*} / 3000+100 f_{0, i}\right)^{-1}$

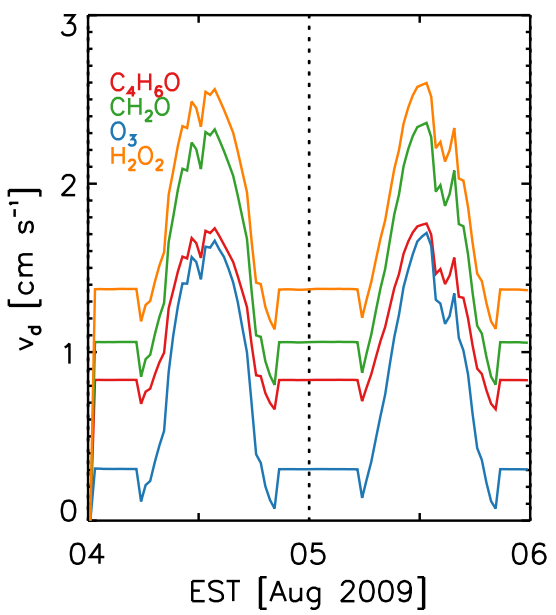

Fig. 1. Simulated canopy-integrated deposition velocity $\left(v_{\mathrm{d}}\right)$ for methacrolein $\left(\mathrm{C}_{4} \mathrm{H}_{6} \mathrm{O}\right)$, formaldehyde $\left(\mathrm{CH}_{2} \mathrm{O}\right)$, ozone $\left(\mathrm{O}_{3}\right)$, and hydrogen peroxide $\left(\mathrm{H}_{2} \mathrm{O}_{2}\right)$.

$R_{\mathrm{c}, i}=R_{\mathrm{c}, \mathrm{O}_{3}}\left(10^{-5} H_{i}^{*}+f_{0, i}\right)^{-1}$.

$f_{0, i}$ follows Wesely (1989) with the exception of MACR and $\mathrm{HCHO}$, which are set to that of $\mathrm{O}_{3}\left(f_{0, i}=1\right)$ in response to recent suggestions that oxidized VOC can decompose in the leaf more rapidly than previously believed (Karl et al., 2004, 2010). Following this change, CACHE simulates canopyintegrated deposition velocities for MACR within the expectations of Karl et al. $\left(2010, v_{d, \text { MACR }}<2.4 \mathrm{~cm} \mathrm{~s}^{-1}\right)$ and comparable to that of $\mathrm{O}_{3}$ (Fig. 1). $\mathrm{H}_{2} \mathrm{O}_{2}$ deposition rates are consistent with previous modeling studies, yet may be underestimated according to recent observational studies (Ganzeveld et al., 2006). Deposition to the ground follows Gao et al. (1993).

\subsubsection{Advection}

Horizontal advection of anthropogenic $\mathrm{NO}_{\mathrm{x}}$ and long-lived VOC is represented in CACHE as a function of wind direction. Cooper et al. (2001) attribute elevated concentrations of $\mathrm{O}_{3}, \mathrm{CO}, \mathrm{NO}_{\mathrm{x}}$, and other oxidized nitrogen species $\left(\mathrm{NO}_{\mathrm{z}}\right)$ observed at PROPHET to southerly flow from Chicago or Detroit and lower mixing ratios to flow from clean Canadian air masses over the Great Lakes. We estimate the directiondependent advection rate of eight RACM species $\left(\mathrm{NO}_{2}\right.$, HCHO, MACR, KET, HC3, HC5, OLT, and OLI; see Stockwell et al. (1997) for full definitions) according to the geographical location of PROPHET relative to nearby major urban centers. Chicago (pop. $\sim 2.9$ million) and Detroit (pop. $\sim 950000$ ) are the major contributors of anthropogenic emissions affecting northern Michigan, with emission inventories for $\mathrm{NO}_{\mathrm{x}}$ and VOC totaling over $20000 \mathrm{~kg} \mathrm{day}^{-1}$, whereas peak $\mathrm{NO}_{\mathrm{x}}$ and VOC emissions from Milwaukee (pop. $\sim 950000$ ) total in the range of $12500-15000 \mathrm{~kg} \mathrm{day}^{-1}$ 
(LADCO, 2010). Therefore, we presume signatures of anthropogenic advection observed at PROPHET to be more pronounced with air originating in Chicago or Detroit over Milwaukee by assuming the strongest advection rates when winds are directly from the south. Westerly advection from Lake Michigan has been associated with lower isoprene concentrations than advection from forests to the south (Sillman et al., 2002); therefore, we add advection of biogenic HCHO and MACR from isoprene oxidation under southerly winds. We incorporate advection of the above species between the heights 45-106 m (22-26 model levels) at the hourly, winddirection-dependent rates shown in Table 2. Measured $\mathrm{NO}_{2}$, $\mathrm{HCHO}$, and MACR concentrations are used to tune advection rates for the model scenario that incorporates both the revised turbulence scheme and RACM-MIM chemistry (hereafter, the MIX+MIM case). Due to the lack of ambient observations, anthropogenic hydrocarbon RACM categories, OLI, OLT, KET, HC3, and HC5, are added to reflect average concentrations of regional pollution events.

\subsubsection{Case study: 4-5 August}

The case study simulation period includes $48 \mathrm{~h}$ starting at 00:00 Eastern Standard Time (EST) on 4 August 2009 and ending at 23:59 EST on 5 August 2009. This two-day period offers the clearest daytime skies within the period when the most chemistry observations are available. We select these clear-sky days because they represent the time period most conducive to BVOC emissions and photochemistry, as well as providing the best measured-modeled agreement for the turbulence parameterization. NCEP surface reanalysis indicates a weak frontal passage occurring at $\sim 07: 00$ EST on 4 August (Fig. S2 in the Supplement), visible in the observed wind direction (Fig. S1 in the Supplement) through a shift from southerly to northwesterly winds. Back-trajectory data (Fig. S2 in the Supplement) show that air originated in northern Illinois (southwest of the PROPHET site) prior to the frontal passage. Following the frontal passage, the source region ranges from northern Minnesota and southwestern Ontario, Canada (west and northwest of the site, respectively). This meteorological scenario allows us to evaluate our advection scheme presented in Sect. 2.2.5 and the ability of the model to capture the shift from polluted- to clean-air advection, while also providing a good comparison between chemistry at PROPHET under the influence of regional transport versus predominantly local chemistry.

\section{Results and discussion}

We compare micrometeorological and chemistry observations from CABINEX 2009 against CACHE simulations during the 4-5 August 2009 case period using four model scenarios:
Table 2. Advection rates for $\mathrm{NO}_{\mathrm{x}}, \mathrm{VOC}$, and other hydrocarbons as a function of wind direction. Rates (in $\mathrm{ppbvh}^{-1}$ ) are scaled by the geostrophic wind speed.

\begin{tabular}{lcc}
\hline RACM species name & $90-135^{\circ}, 225-270^{\circ}$ & $135-225^{\circ}$ \\
\hline $\mathrm{NO}_{2}$ & 0.05 & 0.25 \\
MACR & 0.00 & 1.00 \\
HCHO (anthropogenic) & 0.00 & 0.03 \\
HCHO (biogenic) & 0.00 & 1.00 \\
KET & 0.00 & 0.25 \\
HC3 & 0.00 & $2.50 \times 10^{-4}$ \\
HC5 & 0.00 & 0.25 \\
OLT & 0.00 & 0.13 \\
OLI & 0.00 & 0.01 \\
\hline
\end{tabular}

1. BASE: a control run in which turbulence follows $K_{\mathrm{H} \text {,mod }}$ (Eq. 5) alone and chemistry is according to RACM;

2. MIX: sensitivity of the model to turbulence is tested by modifying $K_{\mathrm{H} \text {,mod }}$ with $K_{\mathrm{H} \text {,obs }}(\mathrm{Eq} .8)$ and $R$ (Eq. 11) to account for near-field effects (Sect. 2.2.1) while using BASE chemistry;

3. MIM: sensitivity of the model to varying treatments of isoprene degradation is tested by replacing RACM with RACM-MIM while using BASE turbulence; and

4. MIX+MIM: the combined effects of enhanced turbulence and biogenic representation are examined by applying MIX turbulence and MIM chemistry.

We first evaluate the modifications made to the turbulent exchange parameterization implemented in the MIX model scenario (Sect. 3.1), followed by an analysis of model-measurement comparisons throughout the canopy and the surface layer (to approximately $3 h$ ) for $\mathrm{O}_{3}$ and $\mathrm{NO}_{\mathrm{x}}$ (Sect. 3.2), BVOC and their oxidation products (Sect. 3.3), and $\mathrm{HO}_{\mathrm{x}}$ concentrations and $\mathrm{OH}$ reactivity (Sect. 3.4).

\subsection{Evaluation of turbulent exchange}

We estimate observed eddy diffusivity $\left(K_{\mathrm{H}, \mathrm{obs}}\right.$, Fig. 2$)$ from sonic anemometer measurements (Eq. 8) at two heights on the PROPHET tower $(0.9 h$ and $1.5 h)$ for the $4-5$ August case study. At $34 \mathrm{~m}, K_{\mathrm{H}, \mathrm{obs}}$ has a strong diurnal cycle ranging from $3 \mathrm{~m}^{2} \mathrm{~s}^{-1}$ at night to $10 \mathrm{~m}^{2} \mathrm{~s}^{-1}$ at midday with nighttime and daytime standard deviations of around 1 and $2 \mathrm{~m}^{2} \mathrm{~s}^{-1}$, respectively. $K_{\mathrm{H} \text {,obs }}$ in the upper canopy is only $1-3 \mathrm{~m}^{2} \mathrm{~s}^{-1}$ lower than above the canopy, with a similar magnitude of standard deviations. The majority of the canopy foliage resides below the $0.9 \mathrm{~h}$ measurement, and the absence of lower canopy micrometeorological measurements is a limiting factor in our estimates of in-canopy mixing.

The original CACHE parameterization of $K_{\mathrm{H}, \bmod }$ (Eq. 5) is below one standard deviation of $K_{\mathrm{H}, \text { obs }}$ at both 


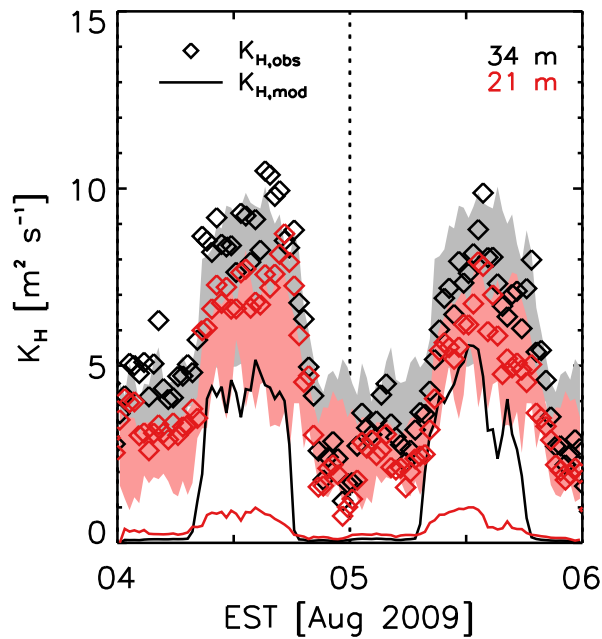

Fig. 2. Observed ( $K_{\mathrm{H} \text {,obs }}$, given by Eq. (8, diamonds)) and modeled

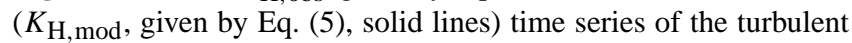
exchange coefficient in the upper-canopy $(20.6 \mathrm{~m}, 0.9 \mathrm{~h}$, red) and above the canopy (34 m, $1.5 \mathrm{~h}$, black) for 4-5 August 2009. Standard deviations of the mean diurnal cycle of $K_{\mathrm{H} \text {,obs }}$ for the sunny and partly sunny days (21, 29 July, 2, 4, 5, and 7 August) are shaded. $K_{\mathrm{H} \text {,obs }}$ is calculated using sonic anemometer estimations of $u_{*}$ and $\sigma_{w}$ (see Sect. 2.2.1).

measurement heights $95 \%$ of the simulation time (Fig. 2). At

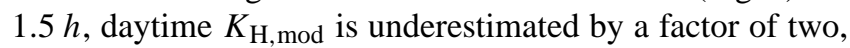
whereas nighttime values are two orders of magnitude below $K_{\mathrm{H} \text {,obs. }} K_{\mathrm{H} \text {,obs }}$ at $0.9 \mathrm{~h}$ are an order of magnitude greater than model estimates over the full simulation period. In addition, the modeled onset of the stable nocturnal boundary layer, represented by the shift from higher, buoyancy-driven mixing to lower, mechanically-driven mixing at the end of the day, occurs two hours earlier and more abruptly than observed. This suggests that the empirical piecewise stability function (Eq. 7) may inadequately capture the formation of the stable layer and/or its effect on turbulence.

We evaluate the MIX turbulence scheme by comparing the BASE and MIX model simulations against observed time series of near-canopy temperatures (Fig. 3) and midday vertical profiles of $K_{\mathrm{H}}$, temperature, primary BVOC (isoprene and monoterpenes), and BVOC oxidation products (formaldehyde, MACR+MVK, and acetaldehyde) (Fig. 4). Following the frontal passage, which CACHE cannot simulate, nearcanopy temperatures are reproduced by the model, especially in the MIX simulation (Fig. 3). This indicates that the PARdriven heating source and vertical exchange of heat at the surface are captured fairly well by the model. $K_{\mathrm{H} \text {,obs }}$, which drives in- and near-canopy turbulence for the MIX case, is twice as large as the BASE-case turbulence (i.e. $K_{\mathrm{H}, \mathrm{mod}}$ ) at $1.5 h$ and an order of magnitude larger at $0.9 h$ (Fig. 4a), indicating missing turbulence such as coherent structures (as observed during CABINEX 2009 Steiner et al., 2011), countergradient terms, or other processes that cannot be captured by
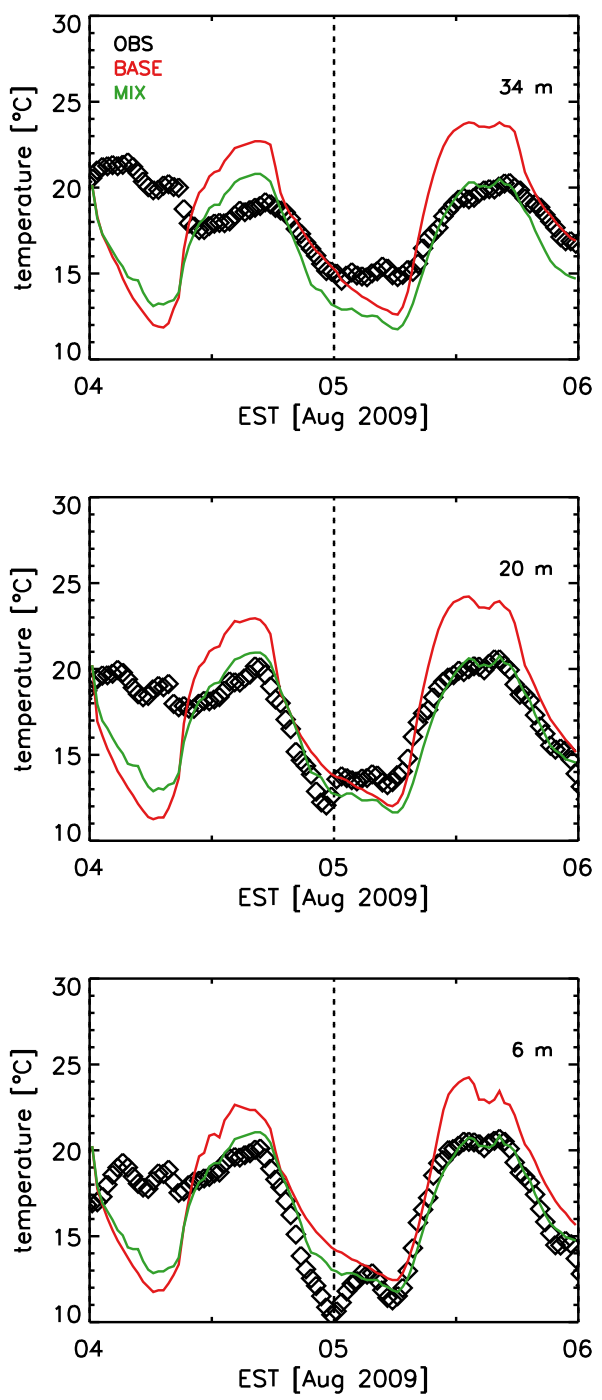

Fig. 3. Measured and modeled temperatures at 34, 20.4, and $6 \mathrm{~m}$.

the original K-theory parameterization. The standard deviations of the $K_{\mathrm{H} \text {,obs }}$ (denoted by the error bars) are based on daily averages for the sunny and partly sunny days during the period of available $u_{*}$ and $\sigma_{w}$ measurements (21, 29 July, 2, 4, 5, and 7 August). Of these "clear-sky" days, observed turbulence was stronger than average on 5 August, leading to nearly uniform temperatures with height that is well captured by the MIX model case (Fig. 4b). In the BASE scenario, $K_{\mathrm{H} \text {,mod }}$ decreases to $0.1 \mathrm{~m}^{2} \mathrm{~s}^{-1}$ at the displacement height, creating an unrealistic artificial boundary. This is an artifact of the use of two different equations to construct the in- and above-canopy wind profiles and turbulence schemes, which creates a discontinuity at the forest-atmosphere interface and prevents BVOC transport out of the canopy sub-layer in the model. Temperature (Fig. 4b) decreases with height within and above the canopy according to the observations, yet the BASE model case imposes a stabilizing inversion induced by 

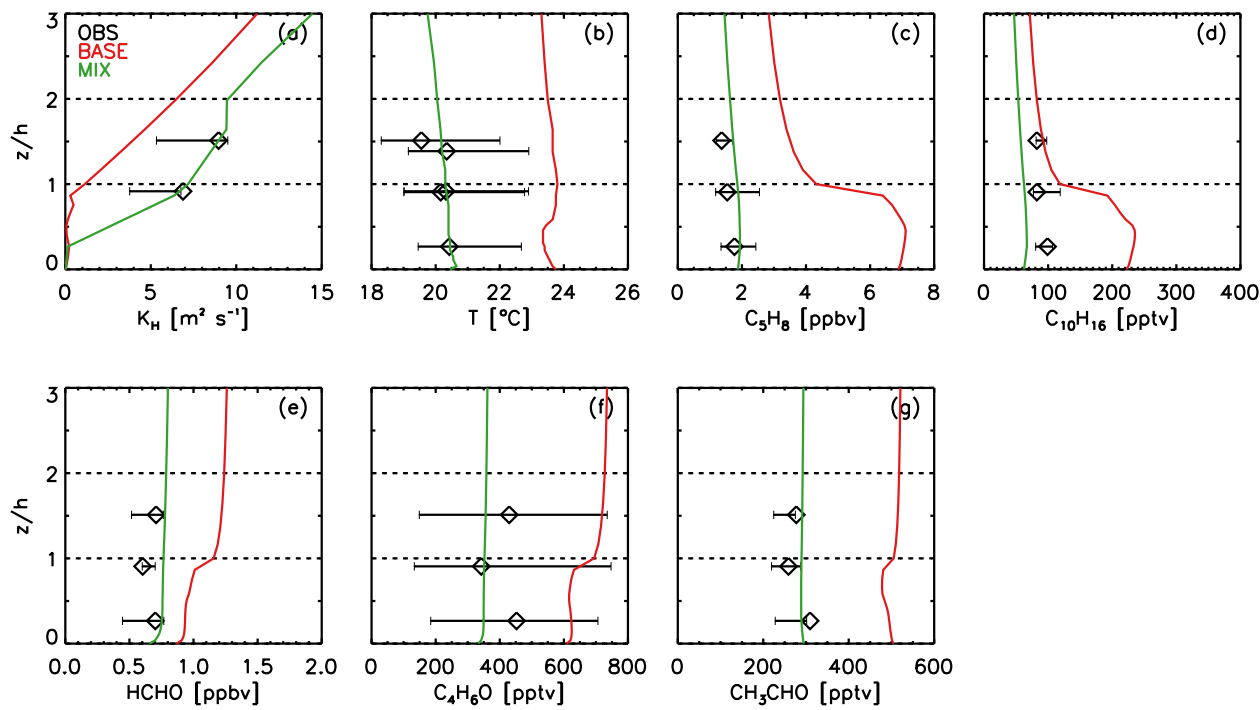

Fig. 4. Measured and modeled vertical profiles of (a) eddy diffusivity, (b) temperature, (c) isoprene, (d) monoterpenes, (e) formaldehyde, (f) MACR+MVK, and (g) acetaldehyde at 14 EST 5 August 2009. Whiskers denote the standard deviations for the sunny and partly sunny days (21, 29 July, 2, 4, 5, and 7 August).

heating of the upper canopy. Consequently, in-canopy mixing is weak in the BASE simulation.

Observed midday vertical gradients of BVOC and oxidation products are also compared against the BASE and MIX simulations in Fig. 4c-g. Enhanced turbulence effectively improves the agreement of modeled and measured concentrations for the more reactive species (isoprene and monoterpenes) by reducing in-canopy concentrations and weakening the vertical gradient. For the longer-lived species (formaldehyde, MACR+MVK, and acetaldehyde), concentrations are decreased and gradients are weakened by the enhanced mixing, leading to a nearly uniform modeled vertical profile in the lowest $60 \mathrm{~m}(3 h)$. Oxidized VOC (e.g., MACR+MVK) can deposit as efficiently as $\mathrm{O}_{3}$ (Karl et al., 2010), yet simulated gradients of these species in the MIX case are weak. This suggests that either a compensation point has been reached or there are some primary sources of oxidized VOC from the forest canopy.

Above the canopy, CACHE accurately captures the characteristic features of the PBL, as indicated by the diurnal cycles of stability and turbulence. During the day, surface heating from canopy absorption of solar radiation induces instability and buoyancy-driven mixing, generating the convective mixed layer. The maximum height of the mixed layer varies with surface heating, but generally peaks mid-day around 1 $\mathrm{km}$ above the surface with a maximum strength occurring at approximately $500 \mathrm{~m}$ as modeled in Gao et al. (1993). At the end of the day, buoyant turbulence ceases in the absence of surface heating, and the stable nocturnal boundary forms beneath a well-mixed residual layer. CACHE does not explicitly model conditions in the free atmosphere nor the existence of an entrainment zone along a capping inversion. Therefore, our study focusses on exchange across the forest-atmosphere interface where we expect little influence from these upper PBL features.

\section{$3.2 \mathrm{O}_{3}$ and $\mathrm{NO}_{\mathrm{x}}$}

We assess the performance of the model in simulating nearcanopy $\mathrm{O}_{3}, \mathrm{NO}_{2}$, and $\mathrm{NO}$ during the $4-5$ August case period (Fig. 5). At all three heights $(6,20.4$, and $34 \mathrm{~m}$ ), observed $\mathrm{O}_{3}$ mixing ratios peak at $40-50 \mathrm{ppbv}$ shortly after the start of the simulation period and subsequently drop by $20 \mathrm{ppbv}$ in $5 \mathrm{~h}$. At that time, backward trajectories produced by the Hybrid Single Particle Lagrangian Integrated (HYSPLIT) model (Fig. S2 in the Supplement) indicate that air parcels observed at PROPHET prior to 08:00 EST on 4 August originated near Milwaukee and Chicago, and parcels arriving after 08:00 EST originated in northern Minnesota and Canada. Additionally, the local wind direction observed at PROPHET (Fig. S1) shifted from southerly to northwesterly over a 3- to 5-h period just after midnight. This transport, concurrent with a peak in observed $\mathrm{NO}_{2}$ concentrations (Fig. 5), highlights the influence of large-scale advection on local $\mathrm{O}_{3}$ and $\mathrm{NO}_{\mathrm{x}}$ concentrations. Despite the inclusion of the same advection scheme in the BASE and MIX cases, the BASE-simulated $\mathrm{O}_{3}$ is reduced after initialization while the concentrations in the MIX case increase to near-observed values. This indicates the influence of turbulent mixing on advection from aloft.

Under clean-air advection (i.e. following the frontal passage discussed in Sect. 2.2.6), above- (Fig. 5a) and uppercanopy (Fig. 5d) $\mathrm{O}_{3}$ measurements show only small variability (e.g., approximately $10 \mathrm{ppbv}$ ) over the remainder of the simulation. BASE simulates a strong diurnal cycle, whereas MIX shows no clear diurnal cycle, indicating that locally 

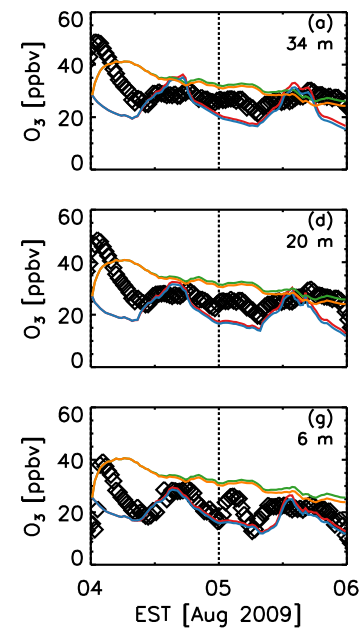
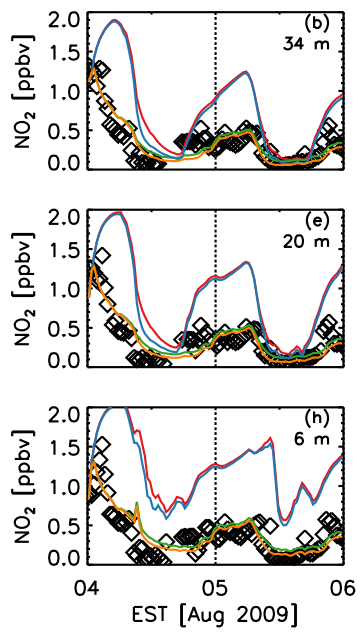
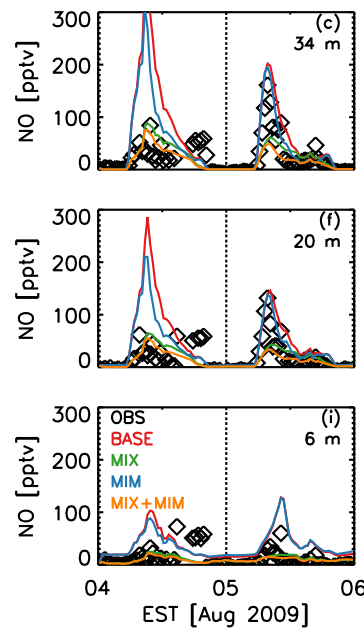

Fig. 5. Measured versus modeled time series for (a, d, g) $\mathrm{O}_{3}$, (b, e, h) $\mathrm{NO}_{2}$, and (c, f, i) NO at $34 \mathrm{~m}, 20.4 \mathrm{~m}$, and $6 \mathrm{~m}$ for the $4-5$ August 2009 simulation period, showing observed concentrations (OBS, black) and modeled concentrations as follows: the original model configuration with modeled turbulence and RACM chemistry (BASE; red); the corrected mixing simulation with RACM chemistry (MIX; green); the original mixing scheme with RACM-MIM chemistry (blue; MIM); and the revised mixing scheme with RACM-MIM chemistry (MIX+MIM; orange).

produced ozone is also highly sensitive to mixing. In the lower canopy (Fig. 5g), $\mathrm{O}_{3}$ measured after the frontal passage is more variable, which is not captured by any of the model simulations. Wind directions are weakly variable from the west to northwest, showing no relationship with changes in $\mathrm{O}_{3}$ concentration, suggesting that advection does not explain the observed variability. At the minima of the variability, lower-canopy concentrations are lower than the upper two measurements, indicating the potential relevance of an important $\mathrm{O}_{3}$ canopy sink. In the canopy layer, deposition is the primary sink of $\mathrm{O}_{3}$, exceeding modeled chemical loss by a factor of 10 . Modeled $\mathrm{O}_{3}$ deposition velocity peaks mid-day at $1.6 \mathrm{~cm} \mathrm{~s}^{-1}$ (Fig. 1), which is higher than other modeling studies $\left(0.4 \mathrm{~cm} \mathrm{~s}^{-1}\right.$, Finkelstein et al., 2000; Stroud et al., 2005), yet yields deposition fluxes that compare quite well with previous observations at PROPHET (15-20 nmol m${ }^{-2} \mathrm{~s}^{-1}$, Hogg et al., 2007). This suggests $\mathrm{O}_{3}$ deposition is fairly well represented in the model. However, midday ozone deposition velocity increases by less than $0.02 \%$ with enhanced mixing, indicating that deposition is not the main driver in the large concentration differences in the BASE and MIX ozone simulations. Lastly, we note that micrometeorological observations were not available in the lower canopy and may be underestimated by the MIX simulation, leading to an uncertainty in lower-canopy turbulence. Consequently, we are unable to evaluate whether these uncertainties in mixing can explain the lower canopy variability. In contrast with turbulent mixing, the enhancement in isoprene degradation between BASE and MIM show little impact on $\mathrm{O}_{3}$ concentrations, indicating that $\mathrm{O}_{3}$ is more sensitive to mixing than chemistry.
Like $\mathrm{O}_{3}$, observed $\mathrm{NO}_{2}$ displays a signature of anthropogenic advection on the early morning of 4 August. In the model, we have tuned the $\mathrm{NO}_{2}$ advection rate (Sect. 2.2.5) to capture the higher concentrations observed at the beginning of the simulation and subsequent lower concentrations as the winds shift following the frontal passage. Observed $\mathrm{NO}_{2}$ ranges from $1.2 \mathrm{ppbv}$ at the beginning of the simulation to approximately $0.5 \mathrm{ppbv}$ on the second night, with midday concentrations of less than $0.1 \mathrm{ppbv}$ after photolysis. MIX+MIM underpredicts $\mathrm{NO}_{2}$ slightly in the early part of the second night, likely due to an oversimplification in our $\mathrm{NO}_{2}$ advection scheme, missing downward transport from the residual layer, or an additional $\mathrm{NO}_{2}$ source (e.g., emission from foliage). NO mixing ratios show a distinct diurnal pattern in the observations, peaking at nearly $180 \mathrm{pptv}$ around mid-morning 5 August at $34 \mathrm{~m}$, consistent with measurements taken over multiple years at PROPHET (Alaghmand et al., 2011). At night, mixing ratios reach as low as $1-5$ pptv. The model reproduces the NO diurnal cycle well at the top of the canopy in all model scenarios, with concentrations overestimated on the first day in the BASE and MIM cases and good agreement for the MIX cases, and underestimated on the second day in the MIX and MIX+MIM cases. NO concentrations decrease with increasing canopy depth as a result of light attenuation lowering the $\mathrm{NO}$ yields from $\mathrm{NO}_{2}$ photolysis. All four model scenarios are able to capture this effect of attenuation reasonably well.

\subsection{Biogenic VOC and oxidation products}

Figure 6 evaluates the four model scenarios against observations for primary BVOC, isoprene and monoterpenes. 

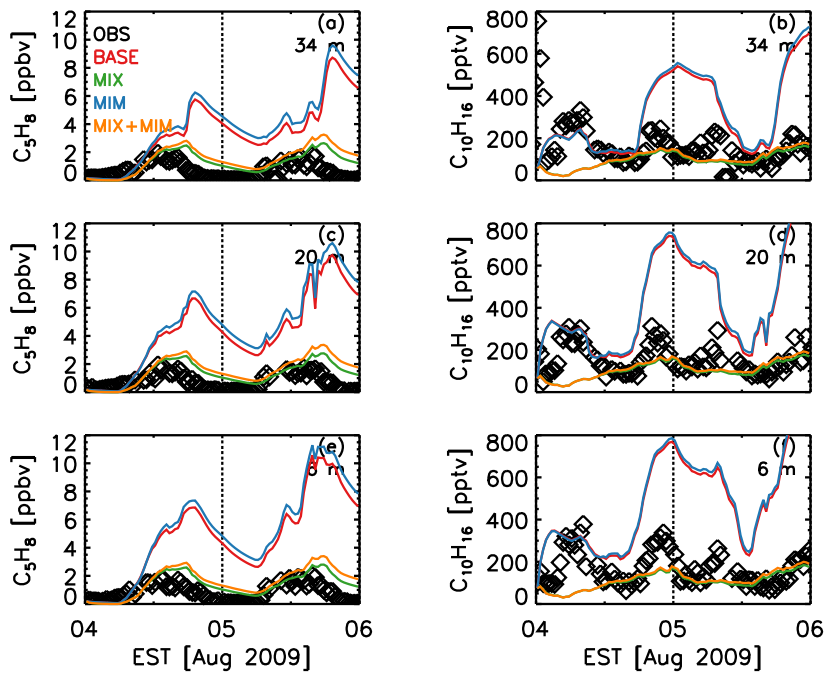

Fig. 6. Same as Fig. 5, but for $(\mathbf{a}, \mathbf{c}, \mathbf{e})$ isoprene and $(\mathbf{b}, \mathbf{d}, \mathbf{f})$ monoterpenes.

Observations of isoprene show a strong diurnal cycle ranging from $0.2 \mathrm{ppbv}$ at night to up to $2-3 \mathrm{ppbv}$ at midday at all height levels. MIM simulations show slightly increased concentrations of isoprene over the BASE simulation, owing to lower $\mathrm{OH}$ availability as enhanced MACR+MVK concentrations increase the competition for $\mathrm{OH}$. However, the BASE and MIM model scenarios have difficulty reproducing this diurnal pattern in two respects: (1) modeled concentrations increase later in the morning than observed, and (2) a rapid increase in concentrations occurs at sunset, causing a large discrepancy between the model and observations. Near the ground, this modeled pattern is dampened with a less pronounced evening peak and better drawdown of concentrations at night. Such a pattern has been frequently observed (cf. Martin et al., 1991), and is prevalent in many modeling studies (e.g., Sillman et al., 2002; Forkel et al., 2006; Barkley et al., 2011), which attribute the end-of-the-day increase to decreased mixing associated with the development of the stable nocturnal boundary layer. As noted in Sect. 3.1, CACHE captures the formation of the stable layer through the development of positive potential temperature gradients and highly reduced turbulent mixing below a well-mixed residual layer. In the BASE simulation, however, rapidly reduced mixing associated with an early and abrupt onset of the stable layer (Sect. 3.1, Fig. 2) leads to accumulation of isoprene (and other BVOC) near the canopy at the end of the day, further indicating the inability of the stability parameter (Eq. 7) to realistically capture the stable layer formation and its effect on turbulent exchange. As demonstrated in the MIX simulation, amplified turbulence and the gradual dissipation of daytime buoyancy-driven turbulence dampens these accumulations. We note, however, that underestimations of modeled in-canopy turbulence due to a lack of micrometeorological measurements in the lower canopy may result in insufficient exchange across the forest-atmosphere boundary. Our evaluation of the BASE and MIX turbulence schemes presented in Sect. 3.1 discusses several observed model-measurement discrepancies in the BASE $K_{\mathrm{H}}$ that are corrected in the MIX scenario, including the end-of-day decrease in mixing at sundown. This indicates the sensitivity of the top-of-canopy BVOC flux to turbulence and emphasizes the importance of an accurate representation of in-canopy mixing in models. Overall, these results highlight the importance of an accurate representation of in-canopy mixing in models and the need for improved simulation the transition from the convective to the nocturnal PBL.

While enhanced mixing improves the diurnal evolution of isoprene, modeled mixing ratios exceed observations on the second day by $1-3$ ppbv, likely due to an underestimate of isoprene oxidation. Oxidation of isoprene in the model is primarily controlled by reaction with $\mathrm{OH}$, with loss rates in the model peaking at midday around $11 \mathrm{pptv} \mathrm{min}^{-1}$ (Fig. 7). Oxidation by ozone follows at much smaller rates (up to 2 pptv $\min ^{-1}$ around sunset) and small contributions by loss with the nitrate radical at night (approximately 0.5 pptv $\mathrm{min}^{-1}$ ). Simulated $\mathrm{NO}_{3}$ mixing ratios at $34 \mathrm{~m}$ (not shown) peak at 4 pptv the first night under elevated $\mathrm{NO}_{2}$ concentrations from regional transport and decrease to $0.3 \mathrm{pptv}$ on the second night when chemistry is dominated by local emissions. Past estimates of $\mathrm{NO}_{3}$ at PROPHET range from 0.4 pptv (Pratt et al., 2012) to $2-3$ pptv (Faloona et al., 2001), although we note that $\mathrm{NO}_{3}$ has not been measured at the site before, making it difficult to evaluate the model. The primary model $\mathrm{NO}_{3}$ source is the nighttime oxidation of $\mathrm{NO}_{2}$ by $\mathrm{O}_{3}$, yet observed $\mathrm{NO}_{2}$ concentrations at the site remain relatively low; therefore, we should expect relatively low concentrations of $\mathrm{NO}_{3}$ and low isoprene- $\mathrm{NO}_{3}$ oxidation rates. A potential explanation for the lack of nighttime oxidation may be $\mathrm{OH}$ concentrations, as discussed in Sect. 3.4. In addition to the effect of nighttime chemistry, Ganzeveld et al. (2008) suggest that downward transport of oxygenated VOC from the residual layer may lower $\mathrm{OH}$ availability, further reducing isoprene oxidation, particularly in the morning. This downward transport is captured in our model for oxygenated VOC during the second morning of the simulation, yet model overestimations of isoprene begin as early as sundown on the prior day, suggesting that the effect of entrained oxygenated VOC from the residual layer on $\mathrm{OH}$ concentrations is likely small relative to the observed discrepancies in nighttime chemistry.

Monoterpenes $\left(\mathrm{C}_{10} \mathrm{H}_{16}\right)$ are grouped together as a total monoterpene concentration by the PTR-MS. As noted at other forest sites (Bouvier-Brown et al., 2009), observations show a different diurnal cycle than isoprene. The early morning and late evening peak (Fig. 6) and higher concentrations at night than during the day have been attributed to high photooxidation during the daytime and an accumulation at night as these temperature-dependent emissions continue in the absence of sunlight. Above the canopy, higher concentrations 


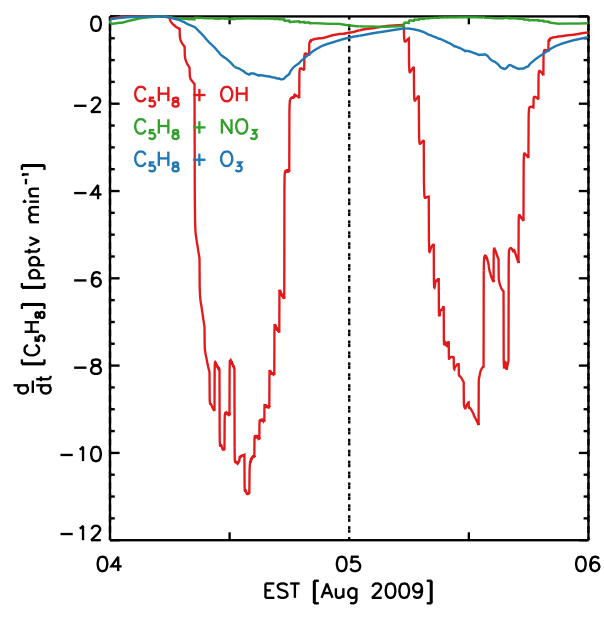

Fig. 7. Modeled isoprene loss rates with respect to reaction with $\mathrm{OH}, \mathrm{NO}_{3}$, and $\mathrm{O}_{3}$ at $34 \mathrm{~m}$ from the MIX case.

of monoterpenes are observed at the beginning of the simulation, suggesting a potential advective source of terpenes to the site in the first six hours of the simulation, which is consistent with air traveling over the forested state. RACMMIM simulates terpene concentrations to be very similar to the RACM case due to no changes in the MIM terpene oxidation scheme. As with isoprene, however, enhanced mixing greatly improves the model-measurement agreement in terms of magnitude of concentrations, though the diurnal cycle is only weakly captured.

Formaldehyde (HCHO) is an important VOC oxidation product and is typically produced in relatively large quantities from the oxidation of isoprene. While anthropogenic VOC can also provide a substantial source of HCHO (Pang et al., 2009), their effect on local HCHO concentrations observed at the PROPHET site is minor (Sumner et al., 2001) unless under advective conditions from the south. Observed mixing ratios at the site are $0.5-1$ ppbv (Fig. 8), reflecting values that are slightly lower than the 1999 field campaign observations (0.5-12 ppbv, Sumner et al., 2001), consistent with the expected reduced photochemistry in the summer of 2009. An advection source is apparent at the beginning of the simulation with higher HCHO concentrations both above and below the canopy (Fig. 8a, d, g). When an advective $\mathrm{HCHO}$ source is added at $45-106 \mathrm{~m}$, measured-modeled comparisons improve above the canopy but not below the canopy, suggesting either that there is in-canopy production that the model does not capture, in-canopy deposition is overestimated, or mixing within the canopy is stronger than simulated. HCHO midday deposition velocity is higher than other studies $\left(2.3 \mathrm{~cm} \mathrm{~s}^{-1}\right.$ in our model as compared to $1.5 \mathrm{~cm} \mathrm{~s}^{-1}$ in Sumner et al. (2001)), yet the model still overestimates $\mathrm{HCHO}$ in all simulations at all heights, even after enhancing the in-leaf reactivity to that of $\mathrm{O}_{3}$, as suggested for other oxidized VOC (Karl et al., 2010). This indicates the possible existence of a compensation point, similar to that observed of other compounds (e.g., $\mathrm{NO}_{2}$, acetone, and methanol, Ganzeveld et al., 2002, 2008), at which the concentration in the plant mesophyll matches or exceeds that of the ambient air, restricting further deposition and potentially inducing emissions.HCHO deposition velocity decreases by less than $0.1 \mathrm{cms}^{-1}$ with enhanced mixing, as with that of $\mathrm{O}_{3}$. When advection is not playing a role (the second day of the simulation), modeled HCHO exhibits a diurnal cycle with higher concentrations during the day especially in the BASE and MIM cases. Both above and below the canopy, the change to MIM increases midday $\mathrm{HCHO}$ concentrations by about $15 \%$ due to larger HCHO yields from BVOC oxidation (Geiger et al., 2003). MIM makes additional HCHO from the isoprene peroxy self-reaction (ISOP+ISOP), plus the new methacrolein peroxy radicals (MACP). Enhanced mixing (MIX and MIX+MIM) weakens the diurnal pattern of $\mathrm{HCHO}$, better reflecting observations.

Other key BVOC oxidation products are the lumped species methacrolein and methyl vinyl ketone (MACR+MVK or $\mathrm{C}_{4} \mathrm{H}_{6} \mathrm{O}$ ). These compounds are detected at the same nominal mass on the PTR-MS and are also lumped in the RACM mechanism. Observed concentrations peak in the early portion of the simulation both above and below the canopy (Fig. 8) due to advection of oxidation products from the south. Adding an advective source of MACR aloft improves measured-modeled agreement at the beginning of the simulation at all measurement heights. The MIX case improves concentrations as compared to observations, yet removes the observed diurnal pattern. Changing to the MIM mechanism doubles the BASE-case concentrations of MACR+MVK due to the increased yield in MACR+MVK by the reaction of first-generation oxidation products of isoprene with NO. Consequently, modeled concentrations of the MACR RACM-MIM surrogate overestimate measured MACR+MVK by a factor of three throughout the profile. This finding is consistent with chamber study comparisons of RACM and RACM-MIM by Geiger et al. (2003), who attribute the result to measurements only accounting for MACR+MVK while the RACM species also includes all other unsaturated $\mathrm{C}_{4}$ carbonyls. Past studies suggest that dry deposition rates for MACR+MVK may be underestimated (Karl et al., 2004, 2010; Pugh et al., 2010), yet the modeled MACR+MVK deposition velocity mid-day peak of $1.6 \mathrm{~cm} \mathrm{~s}^{-1}$ (Fig. 1) compares well with observations by Misztal et al. (2011, 1-2 $\mathrm{cm} \mathrm{s}^{-1}$ ) and Karl et al. (2010, < $2.4 \mathrm{~cm} \mathrm{~s}^{-1}$ ) after modifying the reactivity factor for oxidized VOC following Karl et al. (2010). Enhanced mixing reduces the MACR deposition velocity by about $5 \%$.

We also evaluate the simulation of the biogenic oxidation product hydroxyacetone $\left(\mathrm{C}_{3} \mathrm{H}_{6} \mathrm{O}_{2}\right)$ added to the RACMMIM mechanism (denoted as HACE) representing a major product of MACR+MVK oxidation. While calibrated observations of HACE are not available, the model simulates a diurnal cycle with mixing ratios ranging up to $100 \mathrm{pptv}$ that 

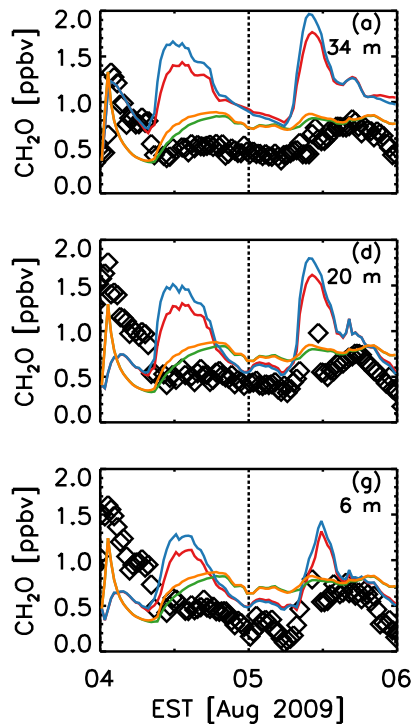
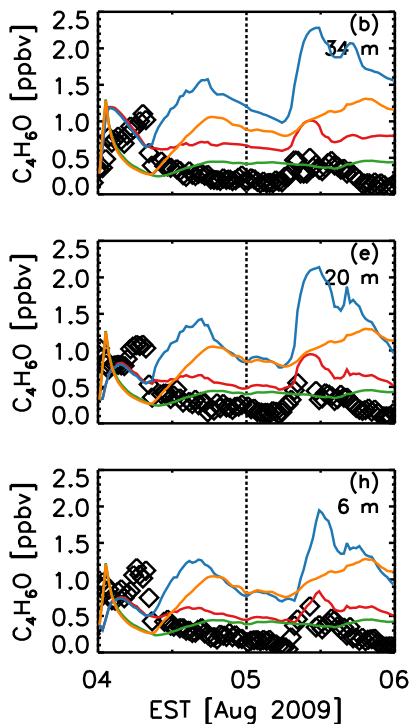
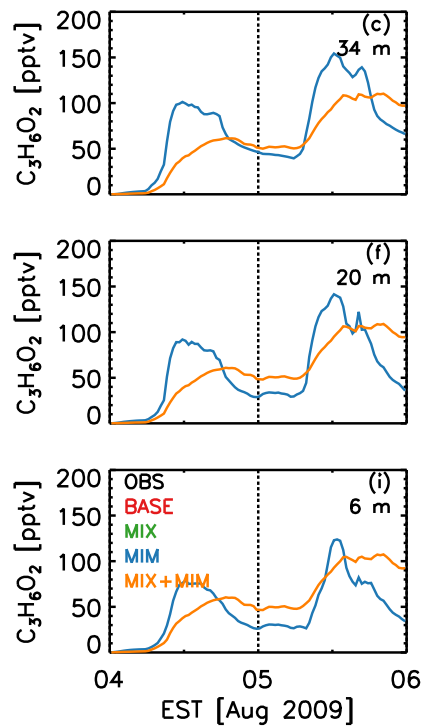

Fig. 8. Same as Fig. 5, but for (a, d, g) formaldehyde, (b, e, h) MACR+MVK, and (c, f, i) hydroxyacetone. Observations of hydroxyacetone are not available.
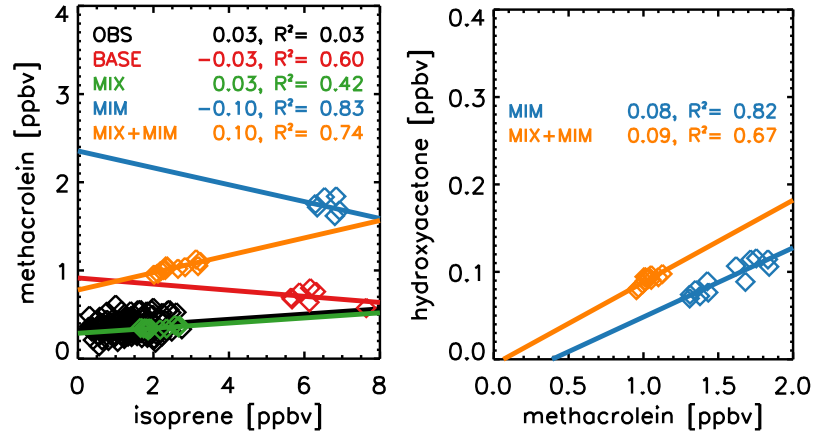

Fig. 9. Measured and modeled correlations between MACR+MVK and isoprene (left), and hydroxyacetone and MACR+MVK (right) at $34 \mathrm{~m}$ for 5 August 2009 between 11:00-17:00 EST. The squared correlation coefficients $\left(R^{2}\right)$ and slopes of the regression lines are given in the upper right-hand corners in colors corresponding to the appropriate model scenario.

decrease slightly with increased mixing (Fig. 8), which is slightly lower than the range of the uncalibrated measurements (200-500 pptv). Glyoxal (GLY) was also measured at the site, with mixing ratios reaching up to $25 \mathrm{pptv}$ during midday, and with a clear advective signal on the first day of the simulations (Fig. S4). However, both RACM versions only form GLY from anthropogenic precursors and do not include the production from any biogenic species; therefore, modeled mixing ratios are on the order of $0.01-1$ pptv. Observations of GLY suggest local biogenic production of GLY, a source that could be included in future models.

We compare the daytime (11:00-17:00 EST) ratios of (MACR+MVK)/isoprene and HACE/(MACR+MVK) to evaluate the ability of the mechanisms to reproduce ob- served BVOC oxidation. Over the full field campaign (not shown), the observed (MACR+MVK)/isoprene ratio is 0.18 , substantially lower than observed in the Amazon (0.44, Karl et al., 2009), yet comparable to observations from previous PROPHET studies (0.12, Apel et al., 2002). Apel et al. (2002) observe lower MACR+MVK concentrations under westerly flow associated with clean-air advection from Lake Michigan, leading to lower MACR+MVK/isoprene ratios. Additionally, as shown by comparing the ratios of MACR+MVK/isoprene with wind direction over the full two-day simulation (Fig. S4 in the Supplement), we observe elevated ratios (0.71) under southerly flow associated with polluted advection. Due to this strong variability in MACR+MVK with respect to wind direction at the PROPHET site, the correlation between MACR+MVK and isoprene is substantially weaker $\left(R^{2}=0.25\right)$ than observed by Karl et al. $\left(2009, R^{2}=0.86\right)$. Figure 9 compares the observed daytime ratios against the four model scenarios for the second day (5 August) to examine local chemistry in the absence of pollution transport. The observed $(\mathrm{MACR}+\mathrm{MVK}) /$ isoprene ratio of 0.03 is much lower than the mean daytime ratio for the full campaign (0.18), likely due to enhanced clean-air advection from the northwest. The BASE and MIM scenarios yield negative ratios, indicating inefficient oxidation of isoprene. This is consistent with the overestimation of isoprene by the BASE and MIM cases, particularly on the second day, as a result of inefficient mixing out of the canopy. In these scenarios, $\mathrm{OH}$ is depleted before isoprene is completely oxidized, leading to insufficient production of MACR+MVK given the amount of isoprene available. This is consistent with past studies, who propose the need for a OH recycling mechanism (Lelieveld et al., 2008). With enhanced mixing (MIX and MIX+MIM scenarios), isoprene is 
oxidized more effectively leading to ratios that correlate well with observations. Additionally, the HACE/(MACR+MVK) relationship can highlight the added oxidation capacity when including the new MACR oxidation pathways in MIM. For local conditions on 5 Aug, the modeled ratios are 0.08 and 0.09 for the MIM and MIX+MIM cases, respectively, both of which are substantially lower than observed in the Amazon (0.3, Karl et al., 2009) due to lower oxidant concentrations. While the MIX+MIM case ratios are lower than the MIM, we note that the correlation is weaker in the MIX+MIM case $\left(R^{2}=0.67\right)$ than in the MIM case $\left(R^{2}=0.82\right)$, indicating a large uncertainty with these ratios.

To summarize, the original CACHE BASE simulations strongly overestimate isoprene concentrations, particularly in the early evening and at nighttime. This is a known problem in models that occurs at all scales (e.g., 1-D models, 3-D models, etc.) and we attribute this increase at the end of the day to improper mixing in the model. The revised mixing scheme, which is based on observed friction velocities and vertical velocity standard deviations, greatly improves the simulation of primary BVOC at most model levels. Therefore, a realistic representation of boundary layer turbulence is critical for modeling forest-canopy exchange and its effect on BVOC chemistry accurately. Oxidation products such as $\mathrm{HCHO}$ and MACR+MVK are overestimated by the BASE model simulations, with the greatest measured-modeled improvement resulting from the change in mixing parameterization versus the chemical mechanism. In general, the more detailed biogenic oxidation scheme (RACM-MIM) increases the oxidation products to three times more than observed, although the mechanism does improve modeled $\mathrm{HO}_{\mathrm{x}}$ as will be discussed in the next section.

\section{$3.4 \mathrm{HO}_{\mathrm{x}}$ and $\mathrm{OH}$ reactivity}

Modeled $\mathrm{OH}$ concentrations reproduce the diurnal cycle and magnitude of observed $\mathrm{OH}\left(1-2.5 \times 10^{6}\right.$ molecules $\mathrm{cm}^{-3}$ at midday) (Fig. 10). Difficulties associated with transmission of laser power to the top of the tower led to few measurements of $\mathrm{OH}$ greater than the limit of the detection of the instrument (approximately $1 \times 10^{6}$ molecules $\mathrm{cm}^{-3}$ ) during this time period; therefore, Fig. 10 displays an average diurnal cycle of $\mathrm{OH}$ of the two simulation days with a peak value of $2 \times 10^{6}$ molecules $\mathrm{cm}^{-3}$. The model produces higher $\mathrm{OH}$ concentrations on the first day of simulation due to the higher oxidation from incoming advection, while modeled concentrations on the second day are approximately half the observed values. The MIX and MIM cases decrease modeled $\mathrm{OH}$ by about 10 and $20 \%$, respectively, on the first day, and on day two, MIX increases modeled OH by about $10 \%$. From the vertical profiles (Fig. 11), in-canopy OH concentrations are low, suggesting small $\mathrm{OH}$ production rates. $\mathrm{OH}$ concentrations are highest above the canopy where substantial production from $\mathrm{O}_{3}$ photolysis and subsequent reaction with $\mathrm{H}_{2} \mathrm{O}$ occurs. In general, enhanced mixing increases the mod- eled $\mathrm{OH}$ concentrations at all heights, whereas the change from RACM to RACM-MIM decreases $\mathrm{OH}$ from the surface to $3 h$. An exception is during the anthropogenic advection event on the morning of 4 August, when enhanced mixing increases above canopy $\mathrm{OH}$ and decreases $\mathrm{OH}$ within the canopy; implementing RACM-MIM increases OH throughout the column, due to increased production from the $\mathrm{HO}_{2}+$ $\mathrm{NO}$ reaction.

For $\mathrm{HO}_{2}$, the measurements show a strong diurnal cycle that is reproduced by the model (Fig. 10). In general, the model underestimates $\mathrm{HO}_{2}$ in the BASE case simulation, with a slight increase in $\mathrm{HO}_{2}$ from the MIM simulation. However, recent studies suggest that the detection of $\mathrm{HO}_{2}$ radicals using chemical conversion to $\mathrm{OH}$ by reaction with added NO may be sensitive to the detection of a fraction of hydroxyalkyl peroxy radicals produced from the $\mathrm{OH}-$ initiated oxidation of alkenes (Fuchs et al., 2011). Calibrations of the Indiana University FAGE instrument indicate that approximately $90 \%$ of isoprene-based hydroxyalkyl peroxy radicals are detected in addition to $\mathrm{HO}_{2}$, while only $5 \%$ of propane-based alkyl peroxy radicals are detected. Given that isoprene dominates the $\mathrm{HO}_{2}$ radical chemistry at this site, the measured $\mathrm{HO}_{2}$ concentrations $\left(\mathrm{HO}_{2}^{*}\right)$ likely reflect the sum of both $\mathrm{HO}_{2}$ and isoprene peroxy radicals (ISOP). In Fig. 10, we compare measured $\mathrm{HO}_{2}^{*}$ with a similar metric from the model $\left(\mathrm{HO}_{2}^{*}=\mathrm{HO}_{2}+\mathrm{ISOP}\right)$ and this greatly improves measured-modeled agreement. The increase in late evening modeled $\mathrm{HO}_{2}^{*}$ is due to an accumulation of the ISOP radicals, an artifact from the end-of-day increase in isoprene concentrations (see Sect. 3.3). When changing to RACM-MIM, the reaction rate for $\mathrm{HO}_{2}+$ ISOP increases and the self-reaction ISOP + ISOP is explicitly added, leading to greater $\mathrm{HO}_{2}^{*}$ destruction and improving the model-measurement agreement. In the vertical profiles (Fig. 11), the model produces a strong source of $\mathrm{HO}_{2}$ above the canopy with some in-canopy production. RACM-MIM increases $\mathrm{HO}_{2}$ throughout the vertical profile, particularly in the daytime. The enhanced mixing (MIX case) increases both in- and above-canopy $\mathrm{HO}_{2}$ concentrations in the morning and above the canopy during the night. Otherwise, slight decreases in $\mathrm{HO}_{2}$ occur. During the advection event on 4 August, increased $\mathrm{NO}_{\mathrm{x}}$ leads to decreased $\mathrm{HO}_{2}$ in both the MIX and MIM cases due to loss with NO.

$\mathrm{OH}$ reactivity $\left(R_{\mathrm{OH}}\right)$ represents the total first order loss rate of $\mathrm{OH}$ (inverse of the $\mathrm{OH}$ lifetime). Measured $R_{\mathrm{OH}}$ values during CABINEX 2009 range from $0-2 \mathrm{~s}^{-1}$ at night to up to $10 \mathrm{~s}^{-1}$ during the day (Fig. 12, left panel), which compare well with previous measurements at PROPHET (Di Carlo et al., 2004). Modeled $R_{\mathrm{OH}}$ is calculated by summing the product of the rate constant and reactant concentrations for all species that consume $\mathrm{OH}$. Modeled $R_{\mathrm{OH}}$ compares best with observations for the MIX scenario, due to the poor reproduction of the observed diurnal cycle of isoprene simulated by the BASE and MIM simulations. This again suggests the dependence of modeled $R_{\mathrm{OH}}$ on the vertical mixing 

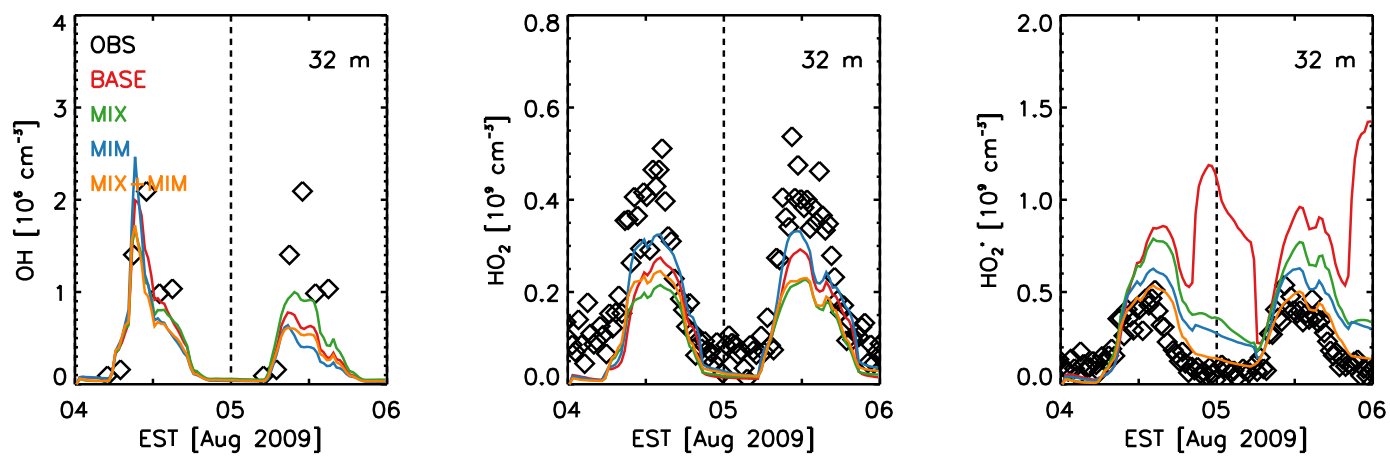

Fig. 10. Same as Fig. 5, but for $\mathrm{OH}$ (left), $\mathrm{HO}_{2}$ (middle), and $\mathrm{HO}_{2}^{*}$ (right) at $32 \mathrm{~m}$.
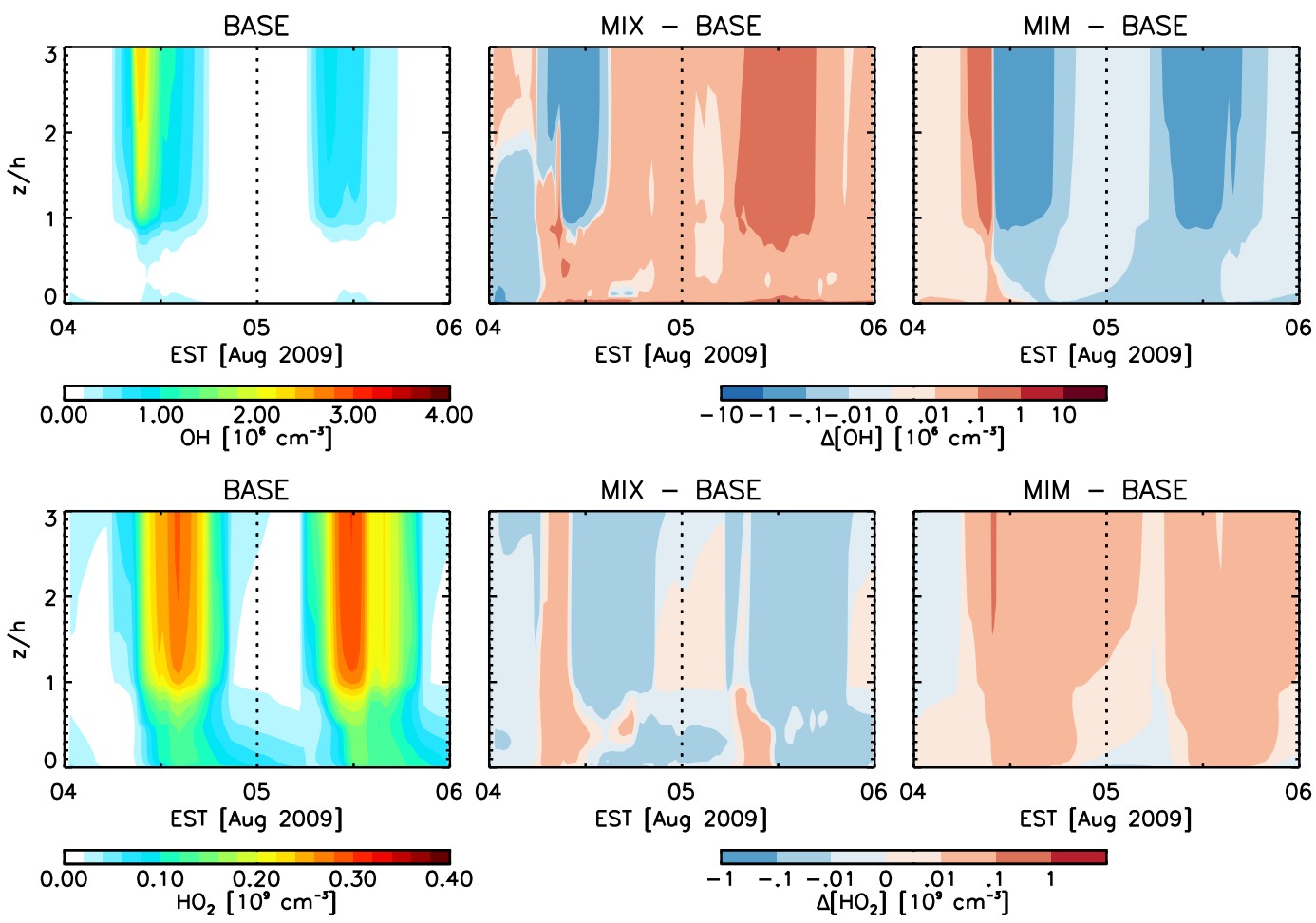

EST [Aug 2009]

EST [Aug 2009]

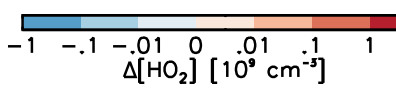

Fig. 11. Vertical profiles of modeled $\mathrm{OH}$ (top) and $\mathrm{HO}_{2}$ (bottom) for the BASE case (left) and the absolute difference between the BASE and MIX cases (middle) and BASE and MIM cases (right). Blue values indicate higher concentrations in the BASE case, and red values indicate higher concentrations in the MIX or MIM cases.

in the model. For modeled $R_{\mathrm{OH}}$, we speciate contributions from BVOC (isoprene, API, LIM) and oxidation productions (HCHO and MACR+MVK). During the afternoon, BVOC account for approximately $85 \%$ of the reactivity in the model, followed by the $\mathrm{CO}$ at $15 \%$, whereas the oxidation products and $\mathrm{CO}$ dominate at night and in the early morning (Fig. 12, right panel). Contributions from methane and $\mathrm{NO}_{2}$ are relatively small. Kim et al. (2011) note that the oxidation products can account for about $8 \%$ of the reactivity if NO concentrations are low. However, as noted by Kim et al. (2011) and Karl et al. (2009), the $R_{\mathrm{OH}}$ tends to increase when photochemically aged air masses arrive at the observa- tion site, which is evident on the first day of the simulation. Because we are including the advection of some primary anthropogenic and secondary oxidation products (Table 2), we correctly model this increase in $R_{\mathrm{OH}}$ on the first day of simulation. The second day of the simulation reflects the local conditions, with slightly lower $R_{\mathrm{OH}}$ that is overestimated by the model.

\section{Summary and conclusions}

This manuscript presents results from a 1-D canopychemistry model, CACHE, applied to a northern Michigan 

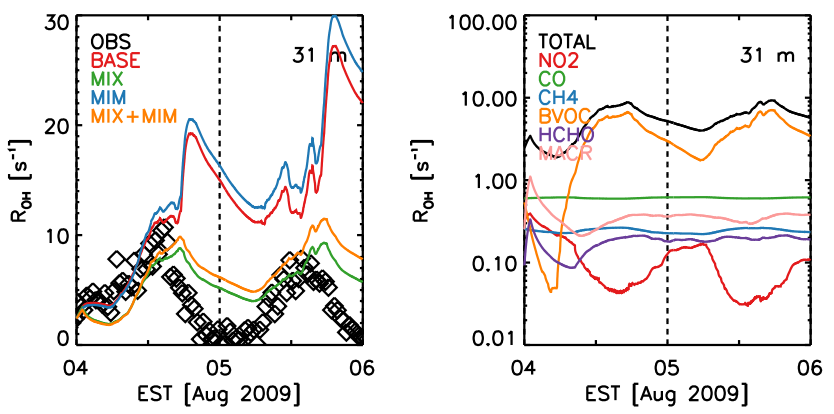

Fig. 12. Total OH reactivity measured (OBS) and modeled (BASE, MIX, MIM, and MIX+MIM) at 30.9 m for 4-5 August 2009 (left); modeled total $\mathrm{OH}$ reactivity and from speciated contributions of $\mathrm{NO}_{2}, \mathrm{CO}, \mathrm{CH}_{4}, \mathrm{BVOC}$ (ISO+API+LIM), HCHO, and MACR for the MIX case (right).

mixed hardwood forest to elucidate in-canopy atmospheric chemistry during the CABINEX 2009 field campaign. CACHE calculates vertical mixing within and above the forest canopy using K-theory, a parameterization used by many 1-D and 3-D models despite its limitations in the canopy roughness layer. Chemical transformation is modeled using RACM, a condensed mechanism that can cover a broad range of chemical situations but with limited BVOC chemistry particularly under low- $\mathrm{NO}_{\mathrm{x}}$ conditions. In this study, we test the model sensitivity of vertical gradients of BVOC and their oxidation products to (1) turbulent exchange and (2) chemistry. First, we account for turbulence in the canopy roughness layer by applying the modified K-theory parameterization of Makar et al. (1999) and adjusting the model with hightime-resolution sonic anemometer measurements of friction velocity and vertical velocity standard deviation. Second, we implement an expanded version of RACM with more explicit BVOC chemistry, RACM-MIM.

Traditional K-theory (i.e. BASE) underestimates forest canopy exchange by $0.5-2$ orders of magnitude, leading to an overly-strong diurnal cycle of ozone, and an overestimate of $\mathrm{NO}_{\mathrm{x}}, \mathrm{BVOC}$ and their oxidation products that accumulate within and above the canopy to 2-3 times higher than observed. This highlights the issue that models with differing turbulence parameterizations in and above the canopy may inhibit exchange across the top of the canopy due to a discontinuity in mixing between the two equations. In addition, traditional K-theory, in which turbulence is driven by a prognostic temperature profile, does not capture the observed gradual onset and termination of convective mixing due to uncertainties with the empirical stability parameter at the transition between stable and unstable conditions. This leads to anomalous spikes in primary BVOC near the canopy, particularly around sunset, that are not present in the observations. Driving near-canopy vertical mixing with micrometeorological observations (e.g., MIX) improves the representation of vertical mixing as evidenced in the improved vertical profiles and diurnal cycles of BVOC and their oxida- tion products. While this parameterization cannot account for asymmetric transport associated with coherent structures and other non-Fickian diffusion processes, this method provides substantial improvement in the model simulations. Adding additional BVOC oxidation pathways with the RACM-MIM mechanism slightly increases isoprene and HCHO (15\%) with greater changes in MACR+MVK ( $80 \%)$, although these concentrations were about five times higher than observed at all heights. Past research suggests that MACR+MVK may constitute only a fraction of the MACR RACM surrogate, and that models may underestimate MACR+MVK surface deposition; however, deposition velocity for MACR+MVK in the model compares well with observations. Changes in $\mathrm{O}_{3}$ and $\mathrm{NO}_{\mathrm{x}}$ concentrations with enhanced isoprene chemistry were negligible. Overall, the parameterizations tested in this study suggest BVOC and their oxidation products can be very sensitive to the mixing parameterization.

The impact of vertical mixing on $\mathrm{HO}_{\mathrm{x}}$ chemistry is dependent on the advection conditions. Advection from polluted regions (e.g., the first day of our simulation) increases $\mathrm{OH}$ in the region of advection (45-106 $\mathrm{m}$ ) and decreases $\mathrm{OH}$ below the level of advection. When local chemistry dominates, an increase in mixing increases $\mathrm{OH}$ concentrations suggesting that the canopy can be a $\mathrm{HO}_{\mathrm{x}}$ source. For $\mathrm{HO}_{2}$, an increase in mixing tends to decrease concentrations regardless of advection conditions. With changes to the RACMMIM chemistry, $\mathrm{OH}$ decreases due to increased secondary oxidation of biogenic oxidation products and $\mathrm{HO}_{2}$ decreases throughout the profile. While the additional BVOC oxidation pathways of RACM-MIM improve $\mathrm{HO}_{2}$, the overestimation of MACR+MVK suggests that the mechanism pathway may not be properly capturing the oxidation of the biogenic oxidation products. Additionally, we find that GLY is underestimated in the model by an order of magnitude (Fig. S3 in the Supplement), suggesting a missing primary biogenic oxidation source.

Typically, 1-D models are subject to several aspects of uncertainty, including (1) the emissions from the canopy and soil, (2) the reactions described by the chemical mechanism, (3) the exchange driven by the turbulence parameterization, and (4) the sink to surface deposition. We have evaluated each of these aspects in this paper, while focussing our sensitivity study on mixing and chemistry. The BVOC emissions have been fairly well-constrained by multiple measurements at the site; however, we find that observed emission factors for isoprene are likely on the lower end of the spectrum due to the unusually cool summer at UMBS. If emission rates were higher than modeled in this study, BVOC concentrations accumulate in the model to unrealistic concentrations. In theory, this could be matched by higher reactivity in the forest, with increased oxidation by $\mathrm{OH}$ through the implementation of an $\mathrm{OH}$ recycling mechanism (Lelieveld et al., 2008) or enhanced deposition of compounds competing for $\mathrm{OH}$ (e.g., oxygenated VOC, Karl et al., 2004, 2010). With enhanced oxygenated VOC deposition according to Karl et al. (2010) 
applied in this study, BVOC still accumulate. OH concentrations were well-matched with the observations; therefore, we did not implement a recycling mechanism in this study. Additionally, underestimations in peroxide (e.g. $\mathrm{H}_{2} \mathrm{O}_{2}$ ) deposition may inhibit in-canopy photochemistry and exchange (Ganzeveld et al., 2006); however, peroxide measurements were not available to constrain deposition rates. We tested the sensitivity of the model to higher $\mathrm{NO}_{\mathrm{x}}$, potentially from a local or advective source by increasing $\mathrm{NO}_{2}$ advection rates until the $\mathrm{NO}_{\mathrm{x}}$ concentrations match urban levels (not shown). With higher isoprene emissions (e.g., the mean value of Ortega et al., 2007), higher $\mathrm{NO}_{\mathrm{x}}$ can increase the oxidation and reduce $\mathrm{BVOC}$ concentrations to observed values, however modeled $\mathrm{NO}_{\mathrm{x}}$ concentrations then exceed observed values by an order of magnitude. It is also possible that $\mathrm{OH}$ concentrations are too low in the model (e.g., Fig. 10, left panel); however, our modeled BVOC oxidation products are already higher than observed and we have good measured-modeled agreement in $\mathrm{OH}$ reactivity. Therefore, we have evidence to show that the modeled emissions and chemistry balance in the model represents the observed conditions fairly accurately.

Overall, we find that an improved representation of incanopy turbulent transport based on micrometeorological observations and a consideration for near-field effects improves the simulation of concentrations and vertical gradients of BVOC and their oxidation products observed during the CABINEX 2009 campaign. The change to a mechanism with more specific BVOC pathways slightly improves agreement with observations for $\mathrm{HO}_{2}$, but produces more BVOC oxidation products than observed (e.g., HCHO, MACR+MVK). While the yields of BVOC oxidation products in MIM may be too high (e.g., Geiger et al., 2003) or surface deposition rates may be too low (Pugh et al., 2010), observed concentrations of these primary oxidation products suggest that our in-canopy oxidation is within the observational constraints. However, we note that implementation of other isoprene oxidation mechanisms may yield different results. Our results show that mixing in the canopy may be more important than changes to BVOC chemistry mechanisms for accurate modeling of BVOC chemistry and forest-atmosphere exchange, and point to the need for a revised in-canopy turbulence parameterization in existing 1-D and 3D atmospheric models. A thorough intercomparison of turbulence and BVOC chemistry data from a variety of forest ecosystems is required to assess the applicability of our results on the global scale. Other aspects of the forest canopy, including the turbulence structure of the lower canopy and the effect of vertical heterogeneity of vegetation (i.e. an understory and overstory of differing plant type) on the oxidation capacity of the canopy and forest-atmosphere exchange of BVOC may provide further information for understanding the vertical profiles of BVOC, their oxidation products, and their contribution to tropospheric chemistry.

\section{Supplementary material related to this article is available online at: http://www.atmos-chem-phys.net/12/ 8829/2012/acp-12-8829-2012-supplement.pdf.}

Acknowledgements. Funding for this work was provided by the National Science Foundation AGS-0904128 to M.A. Carroll and A.L. Steiner at the University of Michigan (UM). Additional support for A.M. Bryan was provided through the University of Michigan Elizabeth C. Crosby Research Foundation and the Michigan Space Grant Consortium. We thank C. Vogel at UMBS for providing ancillary meteorological data for our analysis, as well as Meghan Thurlow, Melissa Galloway, and Anthony O'Brien for providing the glyoxal measurements. We thank the editor (José Fuentes), Laurens Ganzeveld, and an anonymous reviewer for comments that greatly improved this manuscript.

Edited by: J. Williams and J. Fuentes

\section{References}

Alaghmand, M., Shepson, P. B., Starn, T. K., Jobson, B. T., Wallace, H. W., Carroll, M. A., Bertman, S. B., Lamb, B., Edburg, S. L., Zhou, X., Apel, E., Riemer, D., Stevens, P., and Keutsch, F.: The Morning $\mathrm{NO}_{\mathrm{x}}$ maximum in the forest atmosphere boundary layer, Atmos. Chem. Phys. Discuss., 11, 2925129282, doi:10.5194/acpd-11-29251-2011, 2011.

Apel, E. C., Riemer, D. D., Hills, A., Baugh, W., Orlando, J., Faloona, I., Tan, D., Brune, W., Lamb, B., Westberg, H., Carroll, M. A., Thornberry, T., and Geron, C. D.: Measurement and interpretation of isoprene fluxes and isoprene, methacrolein, and methyl vinyl ketone mixing ratios at the PROPHET site during the 1998 Intensive, J. Geophys. Res., 107, 4034, doi:10.1029/2000JD000225, 2002.

Asner, G. P.: Biophysical and Biochemical Sources of Variability in Canopy Reflectance, Remote Sens. Environ., 64, 234-253, doi:10.1016/S0034-4257(98)00014-5, 1998.

Baldocchi, D.: A multi-layer model for estimating sulfur dioxide deposition to a deciduous oak forest canopy, Atmos. Environ., 22, 869-884, doi:10.1016/0004-6981(88)90264-8, 1988.

Baldocchi, D., Falge, E., Gu, L., Olson, R., Hollinger, D., Running, S., Anthoni, P., Bernhofer, C., Davis, K., Evans, R., Fuentes, J., Goldstein, A., Katul, G., Law, B., Lee, X., Malhi, Y., Meyers, T., Munger, W., Oechel, W., Paw U, K. T., Pilegaard, K., Schmid, H. P., Valentini, R., Verma, S., Vesala, T., Wilson, K., and Wofsyn, S.: FLUXNET: A New Tool to Study the Temporal and Spatial Variability of Ecosystem-Scale Carbon Dioxide, Water Vapor, and Energy Flux Densities, B. Am. Meteor. Soc., 82, 24152434, 2001.

Barkley, M. P., Palmer, P. I., Ganzeveld, L., Arneth, A., Hagberg, D., Karl, T., Guenther, A., Paulot, F., Wennberg, P. O., Mao, J., Kurosu, T. P., Chance, K., Müller, J.-F., De Smedt, I., Van Roozendael, M., Chen, D., Wang, Y., and Yantosca, R. M.: Can a "state of the art" chemistry transport model simulate Amazonian tropospheric chemistry?, J. Geophys. Res., 116, D16302, doi:10.1029/2011JD015893, 2011.

Blackadar, A. K.: High-resolution models of the planetary boundary layer, in: Advances in Environmental Science and Engineer- 
ing, 1, 50-85, Gordon and Breech Science Publishers, Inc., New York, USA, 1979.

Bouvier-Brown, N. C., Goldstein, A. H., Gilman, J. B., Kuster, W. C., and de Gouw, J. A.: In-situ ambient quantification of monoterpenes, sesquiterpenes, and related oxygenated compounds during BEARPEX 2007: implications for gas- and particle-phase chemistry, Atmos. Chem. Phys., 9, 5505-5518, doi:10.5194/acp-9-5505-2009, 2009.

Boy, M., Sogachev, A., Lauros, J., Zhou, L., Guenther, A., and Smolander, S.: SOSA - a new model to simulate the concentrations of organic vapours and sulphuric acid inside the ABL Part 1: Model description and initial evaluation, Atmos. Chem. Phys., 11, 43-51, doi:10.5194/acp-11-43-2011, 2011.

Butler, T. M., Taraborrelli, D., Brühl, C., Fischer, H., Harder, H., Martinez, M., Williams, J., Lawrence, M. G., and Lelieveld, J.: Improved simulation of isoprene oxidation chemistry with the ECHAM5/MESSy chemistry-climate model: lessons from the GABRIEL airborne field campaign, Atmos. Chem. Phys., 8, 4529-4546, doi:10.5194/acp-8-4529-2008, 2008.

Carlton, A. G., Wiedinmyer, C., and Kroll, J. H.: A review of Secondary Organic Aerosol (SOA) formation from isoprene, Atmos. Chem. Phys., 9, 4987-5005, doi:10.5194/acp-9-4987-2009, 2009.

Carroll, M. A., Bertman, S. B., and Shepson, P. B.: Overview of the Program for Research on Oxidants: PHotochemistry, Emissions, and Transport (PROPHET) summer 1998 measurements intensive, J. Geophys. Res., 106, 24275-24288, 2001.

Carslaw, N. and Carslaw, D.: The gas-phase chemistry of urban atmospheres, Surv. Geophys., 22, 31-53, 2001.

Claeys, M., Graham, B., Vas, G., Wang, W., Vermeylen, R., Pashynska, V., Cafmeyer, J., Guyon, P., Andreae, M. O., Artaxo, P., and Maenhaut, W.: Formation of Secondary Organic Aerosols Through Photooxidation of Isoprene, Science, 303, 1173-1176, doi:10.1126/science.1092805, 2004.

Cooper, O. R., Moody, J. L., Thornberry, T. D., Town, M. S., and Carroll, M. A.: PROPHET 1998 meteorological overview and air-mass classification, J. Geophys. Res., 106, 24289-24299, 2001.

de Gouw, J. and Warneke, C.: Measurements of volatile organic compounds in the Earth's atmosphere using proton-transferreaction mass spectrometry, Mass. Spectrom. Rev., 26, 223-257, 2007.

Di Carlo, P., Brune, W. H., Martinez, M., Harder, H., Lesher, R., Ren, X., Thornberry, T., Carroll, M. A., Young, V., Shepson, P. B., Riemer, D., Apel, E., and Campbell, C.: Missing OH Reactivity in a Forest: Evidence for Unknown Reactive Biogenic VOCs, Science, 304, 722-725, doi:10.1126/science.1094392, 2004.

Dusanter, S., Vimal, D., Stevens, P. S., Volkamer, R., and Molina, L. T.: Measurements of $\mathrm{OH}$ and $\mathrm{HO}_{2}$ concentrations during the MCMA-2006 field campaign - Part 1: Deployment of the Indiana University laser-induced fluorescence instrument, Atmos. Chem. Phys., 9, 1665-1685, doi:10.5194/acp-9-1665-2009, 2009.

Faloona, I., Tan, D., Brune, W., Hurst, J., Barket, Dennis, J., Couch, T. L., Shepson, P., Apel, E., Riemer, D., Thornberry, T., Carroll, M. A., Sillman, S., Keeler, G. J., Sagady, J., Hooper, D., and Paterson, K.: Nighttime observations of anomalously high levels of hydroxyl radicals above a deciduous forest canopy, J. Geophys. Res., 106, 24315-24333, 2001.
Finkelstein, P. L., Ellestad, T. G., Clarke, J. F., Meyers, T. P., Schwede, D. B., Hebert, E. O., and Neal, J. A.: Ozone and sulfur dioxide dry deposition to forests: Observations and model evaluation, J. Geophys. Res., 105, 15365-15377, 2000.

Finnigan, J.: Turbulence in Plant Canopies, Annu. Rev. Fluid Mech., 32, 519-571, doi:10.1146/annurev.fluid.32.1.519, 2000.

Forkel, R., Seidl, W., Dlugi, R., and Deigele, E.: A OneDimensional Numerical-Model to Simulate Formation and Balance of Sulfate during Radiation Fog Events, J. Geophys. Res., 95, 18501-18515, 1990.

Forkel, R., Klemm, O., Graus, M., Rappenglück, B., Stockwell, W. R., Grabmer, W., Held, A., Hansel, A., and Steinbrecher, R.: Trace gas exchange and gas phase chemistry in a Norway spruce forest: A study with a coupled 1-dimensional canopy atmospheric chemistry emission model, Atmos. Environ., 40, $28-$ 42, doi:10.1016/j.atmosenv.2005.11.070, 2006.

Fuchs, H., Bohn, B., Hofzumahaus, A., Holland, F., Lu, K. D., Nehr, S., Rohrer, F., and Wahner, A.: Detection of $\mathrm{HO}_{2}$ by laserinduced fluorescence: calibration and interferences from $\mathrm{RO}_{2}$ radicals, Atmos. Meas. Tech., 4, 1209-1225, doi:10.5194/amt4-1209-2011, 2011.

Ganzeveld, L., Valverde-Canossa, J., Moortgat, G., and Steinbrecher, R.: Evaluation of peroxide exchanges over a coniferous forest in a single-column chemistry-climate model, Atmos. Environ., 40, 68-80, doi:10.1016/j.atmosenv.2006.01.062, 2006.

Ganzeveld, L., Eerdekens, G., Feig, G., Fischer, H., Harder, H., Königstedt, R., Kubistin, D., Martinez, M., Meixner, F. X., Scheeren, H. A., Sinha, V., Taraborrelli, D., Williams, J., VilàGuerau de Arellano, J., and Lelieveld, J.: Surface and boundary layer exchanges of volatile organic compounds, nitrogen oxides and ozone during the GABRIEL campaign, Atmos. Chem. Phys., 8, 6223-6243, doi:10.5194/acp-8-6223-2008, 2008.

Ganzeveld, L. N., Lelieveld, J., Dentener, F. J., Krol, M. C., Bouwman, A. J., and Roelofs, G. J.: Global soil-biogenic $\mathrm{NO}_{\mathrm{x}}$ emissions and the role of canopy processes, J. Geophys. Res., 107, 4298, doi:10.1029/2001JD001289, 2002.

Gao, W., Wesely, M. L., and Doskey, P. V.: Numerical Modeling of the Turbulent Diffusion and Chemistry of $\mathrm{NO}_{x}, \mathrm{O}_{3}$, Isoprene, and Other Reactive Trace Gases in and Above a Forest Canopy, J. Geophys. Res., 98, 18339-18353, 1993.

Geiger, H., Barnes, I., Bejan, I., Benter, T., and Spittler, M.: The tropospheric degradation of isoprene: an updated module for the regional atmospheric chemistry mechanism, Atmos. Environ., 37, 1503-1519, doi:10.1016/S1352-2310(02)01047-6, 2003.

Goldstein, A. H. and Galbally, I. E.: Known and Unexplored Organic Constituents in the Earth's Atmosphere, Environ. Sci. Technol., 41, 1514-1521, doi:10.1021/es072476p, 2007.

Guenther, A., Hewitt, C. N., Erickson, D., Fall, R., Geron, C., Graedel, T., Harley, P., Klinger, L., Lerdau, M., Mckay, W. A., Pierce, T., Scholes, B., Steinbrecher, R., Tallamraju, R., Taylor, J., and Zimmerman, P.: A global model of natural volatile organic compound emissions, J. Geophys. Res., 100, 8873-8892, 1995.

Hallquist, M., Wenger, J. C., Baltensperger, U., Rudich, Y., Simpson, D., Claeys, M., Dommen, J., Donahue, N. M., George, C., Goldstein, A. H., Hamilton, J. F., Herrmann, H., Hoffmann, T., Iinuma, Y., Jang, M., Jenkin, M. E., Jimenez, J. L., KiendlerScharr, A., Maenhaut, W., McFiggans, G., Mentel, T. F., Monod, A., Prévôt, A. S. H., Seinfeld, J. H., Surratt, J. D., Szmigielski, R., and Wildt, J.: The formation, properties and impact 
of secondary organic aerosol: current and emerging issues, Atmos. Chem. Phys., 9, 5155-5236, doi:10.5194/acp-9-5155-2009, 2009.

Hanson, D. T. and Sharkey, T. D.: Rate of acclimation of the capacity for isoprene emission in response to light and temperature, Plant Cell. Environ., 24, 937-946, doi:10.1046/j.13653040.2001.00745.x, 2001.

Hari, P., Raivonen, M., Vesala, T., Munger, J. W., Pilegaard, K., and Kulmala, M.: Atmospheric science: Ultraviolet light and leaf emission of $\mathrm{NO}_{\mathrm{X}}$, Nature, 422, p. 134, 2003.

Heus, T., van Heerwaarden, C. C., Jonker, H. J. J., Pier Siebesma, A., Axelsen, S., van den Dries, K., Geoffroy, O., Moene, A. F., Pino, D., de Roode, S. R., and Vilà-Guerau de Arellano, J.: Formulation of the Dutch Atmospheric Large-Eddy Simulation (DALES) and overview of its applications, Geosci. Model Dev., 3, 415-444, doi:10.5194/gmd-3-415-2010, 2010.

Hewitt, C. N., Lee, J. D., MacKenzie, A. R., Barkley, M. P., Carslaw, N., Carver, G. D., Chappell, N. A., Coe, H., Collier, C., Commane, R., Davies, F., Davison, B., DiCarlo, P., Di Marco, C. F., Dorsey, J. R., Edwards, P. M., Evans, M. J., Fowler, D., Furneaux, K. L., Gallagher, M., Guenther, A., Heard, D. E., Helfter, C., Hopkins, J., Ingham, T., Irwin, M., Jones, C., Karunaharan, A., Langford, B., Lewis, A. C., Lim, S. F., MacDonald, S. M., Mahajan, A. S., Malpass, S., McFiggans, G., Mills, G., Misztal, P., Moller, S., Monks, P. S., Nemitz, E., Nicolas-Perea, V., Oetjen, H., Oram, D. E., Palmer, P. I., Phillips, G. J., Pike, R., Plane, J. M. C., Pugh, T., Pyle, J. A., Reeves, C. E., Robinson, N. H., Stewart, D., Stone, D., Whalley, L. K., and Yin, X.: Overview: oxidant and particle photochemical processes above a south-east Asian tropical rainforest (the OP3 project): introduction, rationale, location characteristics and tools, Atmos. Chem. Phys., 10, 169-199, doi:10.5194/acp-10-169-2010, 2010.

Hofzumahaus, A., Rohrer, F., Lu, K., Bohn, B., Brauers, T., Chang, C.-C., Fuchs, H., Holland, F., Kita, K., Kondo, Y., Li, X., Lou, S., Shao, M., Zeng, L., Wahner, A., and Zhang, Y.: Amplified Trace Gas Removal in the Troposphere, Science, 324, 17021704, doi:10.1126/science.1164566, 2009.

Hogg, A., Uddling, J., Ellsworth, D., Carroll, M. A., Pressley, S., Lamb, B., and Vogel, C.: Stomatal and non-stomatal fluxes of ozone to a northern mixed hardwood forest, Tellus B, 59, 514525, doi:10.1111/j.1600-0889.2007.00269.x, 2007.

Huisman, A. J., Hottle, J. R., Galloway, M. M., DiGangi, J. P., Coens, K. L., Choi, W., Faloona, I. C., Gilman, J. B., Kuster, W. C., de Gouw, J., Bouvier-Brown, N. C., Goldstein, A. H., LaFranchi, B. W., Cohen, R. C., Wolfe, G. M., Thornton, J. A., Docherty, K. S., Farmer, D. K., Cubison, M. J., Jimenez, J. L., Mao, J., Brune, W. H., and Keutsch, F. N.: Photochemical modeling of glyoxal at a rural site: observations and analysis from BEARPEX 2007, Atmos. Chem. Phys., 11, 8883-8897, doi:10.5194/acp-118883-2011, 2011.

Hurst, J. M., Barket, Dennis J., J., Herrera-Gomez, O., Couch, T. L., Shepson, P. B., Faloona, I., Tan, D., Brune, W., Westberg, H., Lamb, B., Biesenthal, T., Young, V., Goldstein, A., Munger, J. W., Thornberry, T., and Carroll, M. A.: Investigation of the nighttime decay of isoprene, J. Geophys. Res., 106, 24335-24346, 2001.

Jarvis, P. G.: The interpretation of the variations in leaf water potential and stomatal conductance found in canopies in the field, Philos. T. Roy. Soc. B, 273, 593-610, 1976.
Jobson, B. T. and McCoskey, J. K.: Sample drying to improve HCHO measurements by PTR-MS instruments: laboratory and field measurements, Atmos. Chem. Phys., 10, 1821-1835, doi:10.5194/acp-10-1821-2010, 2010.

Karl, T., Potosnak, M., Guenther, A., Clark, D., Walker, J., Herrick, J. D., and Geron, C.: Exchange processes of volatile organic compounds above a tropical rain forest: Implications for modeling tropospheric chemistry above dense vegetation, J. Geophys. Res., 109, D18306, doi:10.1029/2004JD004738, 2004.

Karl, T., Guenther, A., Turnipseed, A., Tyndall, G., Artaxo, P., and Martin, S.: Rapid formation of isoprene photo-oxidation products observed in Amazonia, Atmos. Chem. Phys., 9, 7753-7767, doi:10.5194/acp-9-7753-2009, 2009.

Karl, T., Harley, P., Emmons, L., Thornton, B., Guenther, A., Basu, C., Turnipseed, A., and Jardine, K.: Efficient Atmospheric Cleansing of Oxidized Organic Trace Gases by Vegetation, Science, 330, 816-819, doi:10.1126/science.1192534, 2010.

Kim, S., Guenther, A., Karl, T., and Greenberg, J.: Contributions of primary and secondary biogenic VOC tototal $\mathrm{OH}$ reactivity during the CABINEX (Community Atmosphere-Biosphere INteractions Experiments)-09 field campaign, Atmos. Chem. Phys., 11, 8613-8623, doi:10.5194/acp-11-8613-2011, 2011.

Kim, S. W., Barth, M. C., and Trainer, M.: Influence of fair-weather cumulus clouds on isoprene chemistry, J. Geophys. Res., 117, D10302, doi:10.1029/2011JD017099, 2012.

Kovacs, T. A. and Brune, W. H.: Total OH Loss Rate Measurement, J. Atmos. Chem., 39, 105-122, doi:10.1023/A:1010614113786, 2001.

Krol, M. C., Molemaker, M. J., and Vilà-Guerau de Arellano, J.: Effects of turbulence and heterogeneous emissions on photochemically active species in the convective boundary layer, J. Geophys. Res., 105, 6871-6884, 2000.

LADCO: Regional Network Assessment: States of Illinois, Indiana, Michigan, Minnesota, Ohio, and Wisconsin, Tech. rep., Lake Michigan Air Directors Consortium (LADCO), Des Plaines, IL, http://www.ladco.org/reports/general/Regional_Network Assessment/Regional_Network_Assessment_Report_Version_5. 0_May_27_2010.pdf, draft report, 27 May 2010.

Lelieveld, J., Butler, T. M., Crowley, J. N., Dillon, T. J., Fischer, H., Ganzeveld, L., Harder, H., Lawrence, M. G., Martinez, M., Taraborrelli, D., and Williams, J.: Atmospheric oxidation capacity sustained by a tropical forest, Nature, 452, 737-740, 2008.

Logan, J. A.: Tropospheric Ozone: Seasonal Behavior, Trends, and Anthropogenic Influence, J. Geophys. Res., 90, 10463-10482, 1985.

Makar, P. A., Fuentes, J. D., Wang, D., Staebler, R. M., and Wiebe, H. A.: Chemical processing of biogenic hydrocarbons within and above a temperate deciduous forest, J. Geophys. Res., 104, 35813603, 1999.

Martin, R. S., Westberg, H., Allwine, E., Ashman, L., Farmer, J. C., and Lamb, B.: Measurement of isoprene and its atmospheric oxidation products in a central Pennsylvania deciduous forest, J. Atmos. Chem., 13, 1-32, doi:10.1007/BF00048098, 1991.

Martin, S. T., Andreae, M. O., Althausen, D., Artaxo, P., Baars, H., Borrmann, S., Chen, Q., Farmer, D. K., Guenther, A., Gunthe, S. S., Jimenez, J. L., Karl, T., Longo, K., Manzi, A., Müller, T., Pauliquevis, T., Petters, M. D., Prenni, A. J., Pöschl, U., Rizzo, L. V., Schneider, J., Smith, J. N., Swietlicki, E., Tota, J., Wang, J., Wiedensohler, A., and Zorn, S. R.: An overview of the Ama- 
zonian Aerosol Characterization Experiment 2008 (AMAZE08), Atmos. Chem. Phys., 10, 11415-11438, doi:10.5194/acp10-11415-2010, 2010.

Meyers, T. P.: The sensitivity of modeled $\mathrm{SO}_{2}$ fluxes and profiles to stomatal and boundary layer resistances, Water Air Soil Poll., 35, 261-278, doi:10.1007/BF00290935, 1987.

Meyers, T. P. and Baldocchi, D. D.: A comparison of models for deriving dry deposition fluxes of $\mathrm{O}_{3}$ and $\mathrm{SO}_{2}$ to a forest canopy, Tellus B, 40B, 270-284, doi:10.1111/j.16000889.1988.tb00297.x, 1988.

Misztal, P. K., Nemitz, E., Langford, B., Di Marco, C. F., Phillips, G. J., Hewitt, C. N., MacKenzie, A. R., Owen, S. M., Fowler, D., Heal, M. R., and Cape, J. N.: Direct ecosystem fluxes of volatile organic compounds from oil palms in South-East Asia, Atmos. Chem. Phys., 11, 8995-9017, doi:10.5194/acp-11-89952011, 2011.

Molemaker, M. J. and Vilà-Guerau de Arellano, J.: Control of Chemical Reactions by Convective Turbulence in the Boundary Layer, J. Atmos. Sci., 55, 568-579, 1998.

Ortega, J. and Helmig, D.: Approaches for quantifying reactive and low-volatility biogenic organic compound emissions by vegetation enclosure techniques - Part A, Chemosphere, 72, 343-364, doi:10.1016/j.chemosphere.2007.11.020, 2008.

Ortega, J., Helmig, D., Guenther, A., Harley, P., Pressley, S., and Vogel, C.: Flux estimates and $\mathrm{OH}$ reaction potential of reactive biogenic volatile organic compounds (BVOCs) from a mixed northern hardwood forest, Atmos. Environ., 41, 5479-5495, doi:10.1016/j.atmosenv.2006.12.033, 2007.

Pang, X., Mu, Y., Zhang, Y., Lee, X., and Yuan, J.: Contribution of isoprene to formaldehyde and ozone formation based on its oxidation products measurement in Beijing, China, Atmos. Environ., 43, 2142-2147, doi:10.1016/j.atmosenv.2009.01.022, 2009.

Patton, E., Davis, K., Barth, M., and Sullivan, P.: Decaying Scalars Emitted By A Forest Canopy: A Numerical Study, Bound.-Lay. Meteor., 100, 91-129, doi:10.1023/A:1019223515444, 2001.

Paulot, F., Crounse, J. D., Kjaergaard, H. G., Kroll, J. H., Seinfeld, J. H., and Wennberg, P. O.: Isoprene photooxidation: new insights into the production of acids and organic nitrates, Atmos. Chem. Phys., 9, 1479-1501, doi:10.5194/acp-9-1479-2009, 2009.

Peeters, J., Nguyen, T. L., and Vereecken, L.: $\mathrm{HO}_{x}$ radical regeneration in the oxidation of isoprene, Phys. Chem. Chem. Phys., 11, 5935-5939, doi:10.1039/B908511-D, 2009.

Perterer, J. and Körner, C.: The problem of reference parameters in physiological-ecological research with conifer needles, Forstwissenschaftliches Centralblatt, 109, 220-241, 1990.

Pétron, G., Harley, P., Greenberg, J., and Guenther, A.: Seasonal temperature variations influence isoprene emission, Geophys. Res. Lett., 28, 1707-1710, 2001.

Poisson, N., Kanakidou, M., and Crutzen, P. J.: Impact of Non-Methane Hydrocarbons on Tropospheric Chemistry and the Oxidizing Power of the Global Troposphere: 3Dimensional Modelling Results, J. Atmos. Chem., 36, 157-230, doi:10.1023/A:1006300616544, 2000.

Pöschl, U., von Kuhlmann, R., Poisson, N., and Crutzen, P. J.: Development and Intercomparison of Condensed Isoprene Oxidation Mechanisms for Global Atmospheric Modeling, J. Atmos. Chem., 37, 29-52, doi:10.1023/A:1006391009798, 2000.
Pratt, K. A., Mielke, L. H., Shepson, P. B., Bryan, A. M., Steiner, A. L., Ortega, J., Daly, R., Helmig, D., Vogel, C. S., Griffith, S., Dusanter, S., Stevens, P. S., and Alaghmand, M.: A onedimensional model study of individual reactive biogenic volatile organic compounds and their contributions to organic nitrates above a mixed forest, Atmos. Chem. Phys. Discuss., submitted, 2012.

Pressley, S., Lamb, B., Westberg, H., Flaherty, J., Chen, J., and Vogel, C.: Long-term isoprene flux measurements above a northern hardwood forest, J. Geophys. Res., 110, D07301, doi:10.1029/2004JD005523, 2005.

Pugh, T. A. M., MacKenzie, A. R., Hewitt, C. N., Langford, B., Edwards, P. M., Furneaux, K. L., Heard, D. E., Hopkins, J. R., Jones, C. E., Karunaharan, A., Lee, J., Mills, G., Misztal, P., Moller, S., Monks, P. S., and Whalley, L. K.: Simulating atmospheric composition over a South-East Asian tropical rainforest: performance of a chemistry box model, Atmos. Chem. Phys., 10, 279-298, doi:10.5194/acp-10-279-2010, 2010.

Raupach, M. R.: A practical Lagrangian method for relating scalar concentrations to source distributions in vegetation canopies, Q. J. Roy. Meteor. Soc., 115, 609-632, doi:10.1002/qj.49711548710, 1989.

Raupach, M. R., Finnigan, J. J., and Brunei, Y.: Coherent eddies and turbulence in vegetation canopies: The mixing-layer analogy, Bound.-Lay. Meteor., 78, 351-382, doi:10.1007/BF00120941, 1996.

Schmid, H. P., Su, H.-B., Vogel, C. S., and Curtis, P. S.: Ecosystematmosphere exchange of carbon dioxide over a mixed hardwood forest in northern lower Michigan, J. Geophys. Res., 108, 4417, doi:10.1029/2002JD003011, 2003.

Sillman, S., Carroll, M. A., Thornberry, T., Lamb, B. K., Westberg, H., Brune, W. H., Faloona, I., Tan, D., Shepson, P. B., Sumner, A. L., Hastie, D. R., Mihele, C. M., Apel, E. C., Riemer, D. D., and Zika, R. G.: Loss of isoprene and sources of nighttime $\mathrm{OH}$ radicals at a rural site in the United States: Results from photochemical models, J. Geophys. Res., 107, 4043, doi:10.1029/2001JD000449, 2002.

Simpson, D., Guenther, A., Hewitt, C. N., and Steinbrecher, R.: Biogenic emissions in Europe 1. Estimates and uncertainties, J. Geophys. Res., 100, 22875-22890, 1995.

Stavrakou, T., Peeters, J., and Müller, J.-F.: Improved global modelling of $\mathrm{HO}_{x}$ recycling in isoprene oxidation: evaluation against the GABRIEL and INTEX-A aircraft campaign measurements, Atmos. Chem. Phys., 10, 9863-9878, doi:10.5194/acp-10-98632010, 2010.

Steinbrecher, R., Hauff, K., Hakola, H., and Rössler, J.: A Revised Parametrisation for Emission Modelling of Isoprenoids for Boreal Plants, in: Biogenic VOC emissions and photochemistry in the boreal regions of Europe - Biphorep, edited by Laurila, T. and Lindfors, V., no. 70 in Air pollution research report, pp. 2943, Commission of the European Communities, EUR 18910 EN. EC, Brussels, 1999.

Steiner, A. L., Pressley, S. N., Botros, A., Jones, E., Chung, S. H., and Edburg, S. L.: Analysis of coherent structures and atmosphere-canopy coupling strength during the CABINEX field campaign, Atmos. Chem. Phys., 11, 11921-11936, doi:10.5194/acp-11-11921-2011, 2011.

Stevens, P., Mather, J., and Brune, W.: Measurement of tropospheric $\mathrm{OH}$ and $\mathrm{HO}_{2}$ by laser-induced fluorescence at low pressure, J. 
Geophys. Res., 99, 3543-3557, 1994.

Stockwell, W. R., Kirchner, F., Kuhn, M., and Seefeld, S.: A new mechanism for regional atmospheric chemistry modeling, J. Geophys. Res., 102, 25847-25879, 1997.

Stroud, C., Makar, P., Karl, T., Guenther, A., Geron, C., Turnipseed, A., Nemitz, E., Baker, B., Potosnak, M., and Fuentes, J. D.: Role of canopy-scale photochemistry in modifying biogenicatmosphere exchange of reactive terpene species: Results from the CELTIC field study, J. Geophys. Res., 110, D17303, doi:10.1029/2005JD005775, 2005.

Stull, R. B.: An Introduction to Boundary Layer Meteorology, p. 382, Kluwer Academic Publishers, Dordrecht/Boston/London, 1988.

Sumner, A. L., Shepson, P. B., Couch, T. L., Thornberry, T., Carroll, M. A., Sillman, S., Pippin, M., Bertman, S., Tan, D., Faloona, I., Brune, W., Young, V., Cooper, O., Moody, J., and Stockwell, W.: A study of formaldehyde chemistry above a forest canopy, J. Geophys. Res., 106, 24387-24405, 2001.

Tan, D., Faloona, I., Simpas, J. B., Brune, W., Shepson, P. B., Couch, T. L., Sumner, A. L., Carroll, M. A., Thornberry, T., Apel, E., Riemer, D., and Stockwell, W.: $\mathrm{HO}_{x}$ budgets in a deciduous forest: Results from the PROPHET summer 1998 campaign, J. Geophys. Res., 106, 24407-24427, 2001.
Wesely, M. L.: Parameterization of surface resistances to gaseous dry deposition in regional-scale numerical models, Atmos. Environ., 23, 1293-1304, doi:10.1016/0004-6981(89)90153-4, 1989.

Wolfe, G. M. and Thornton, J. A.: The Chemistry of AtmosphereForest Exchange (CAFE) Model - Part 1: Model description and characterization, Atmos. Chem. Phys., 11, 77-101, doi:10.5194/acp-11-77-2011, 2011.

Wolfe, G. M., Thornton, J. A., Bouvier-Brown, N. C., Goldstein, A. H., Park, J.-H., McKay, M., Matross, D. M., Mao, J., Brune, W. H., LaFranchi, B. W., Browne, E. C., Min, K.-E., Wooldridge, P. J., Cohen, R. C., Crounse, J. D., Faloona, I. C., Gilman, J. B., Kuster, W. C., de Gouw, J. A., Huisman, A., and Keutsch, F. N.: The Chemistry of Atmosphere-Forest Exchange (CAFE) Model - Part 2: Application to BEARPEX-2007 observations, Atmos. Chem. Phys., 11, 1269-1294, doi:10.5194/acp-11-12692011, 2011. 